\title{
Poder de Mercado no Segmento de Distribuição de Gasolina C: Uma Análise a partir da Nova Organização Industrial Empírica
}

\author{
Rosangela Aparecida Soares Fernandes \\ Professora - Universidade Federal de Ouro Preto \\ Endereço para contato: Rua do Catete, 166 - Centro - Mariana, MG \\ CEP: 35420-000 - E-mail: roaeconomista@yahoo.com.br \\ Marcelo José Braga \\ Professor - Universidade Federal de Viçosa \\ Endereço para contato: Av. P. H. Rolfs, s/n - Campus Universitário - Viçosa - MG \\ CEP: 36570-000 - E-mail: mjbraga@ufv.br
}

Recebido em 02 de julho de 2011. Aceito em 07 de maio de 2013.

\section{Resumo}

Este artigo tem como objetivo avaliar o grau de poder de mercado no setor de distribuição de gasolina C, nas regiões brasileiras, no período de 2002 a 2008. Para tal, baseou-se na Teoria da Nova Organização Industrial Empírica (NOIE), especificamente, no modelo proposto por Bresnahan (1982) e Lau (1982). Uma versão dinâmica do modelo também foi estimada. Os resultados indicaram que, exceto para a região Norte, para o modelo estático, as empresas distribuidoras de gasolina $\mathrm{C}$ não agem como tomadoras de preços $(\Lambda=0)$. No outro extremo, a hipótese de conluio perfeito $(\Lambda=1)$ entre elas foi rejeitada. Verificou-se que, em várias regiões, os parâmetros revelaram-se suficientemente baixos, sugerindo que as empresas distribuidoras apresentam elevada competição entre si.

\section{Palavras-Chave}

poder de mercado, gasolina $\mathrm{C}$, economia industrial

\begin{abstract}
This study aims to assess the degree of market power in the distribution sector gasoline C, in Brazilian regions, from 2002 to 2008. To this end, based on the Theory of the New Empirical Industrial Organization (NOIE), specifically, the model proposed by Bresnahan (1982) and Lau (1982). A dynamic version of the model was also estimated. The results indicated that, except for the northern region to the static model, the distributors of gasoline $C$ does not act as price takers. At the other extreme, the hypothesis of perfect collusion between them was rejected. It was found that, in many regions, parameters proved to be sufficiently low, suggesting that the distributors have high competition with each other.
\end{abstract}




\section{Keywords}

market power, gasoline $\mathrm{C}$, industrial economic

\section{JEL Classification}

L 11, L 13

\section{Introdução}

O setor de distribuição de gasolina $\mathrm{C}$ apresenta características que potencializam o exercício de poder de mercado por parte de suas empresas. ${ }^{1}$ Segundo dados da Agência Nacional de Petróleo - ANP (2009a), as quatro maiores empresas que atuam no mercado nacional detém cerca de $68 \%$ do volume total de vendas da gasolina C. Regionalmente, a concentração também é relativamente elevada. Em 2008, a razão de concentração das 4 maiores distribuidoras nas regiões Sudeste, Sul, Nordeste, Norte e Centro-Oeste foram de $71,3 \%, 72,7 \%, 62,2 \%, 68 \%, 65,9 \%$, respectivamente. Apesar da concentração não implicar, necessariamente, que o mercado se comporta de forma não competitiva, suspeitas sobre a conduta anticoncorrencial por parte das distribuidoras são frequentemente levantadas. No Sistema Brasileiro de Defesa da Concorrência (SBDC), o setor com o maior número de investigações envolvendo cartéis é o de combustíveis líquidos (Bruni, 2005).

Além da concentração, algumas características da demanda e da estrutura de oferta desse combustível, viabilizam o comportamento anticompetitivo por parte das distribuidoras. Não são muitos os substitutos próximos da gasolina $\mathrm{C}$ que representem alternativas para o abastecimento dos automóveis e comerciais leves, pelo menos no curto prazo, em razão da restrição tecnológica dos veículos. Especificamente, para o abastecimento dos automóveis movidos exclusivamente à gasolina, a possibilidade de utilização de outro combustível é de fato nula. Por outro lado, para os proprietários de veículos com tecnologia flex, o álcool hidratado representa a única alternativa. Com relação à oferta, há evidências de barreiras à entrada neste setor, em decorrência de desvantagens econômicas das firmas entrantes em relação às empresas estabelecidas, relacionadas

1 A gasolina C é a gasolina comum comercializada nos postos revendedores e utilizada em automóveis e comerciais leves. Este combustível é preparado pelas companhias distribuidoras que adicionam álcool etílico anidro à gasolina do tipo $\mathrm{A}$. $\mathrm{O}$ teor de álcool na gasolina final atinge à faixa de 21 a 25 por cento em volume, conforme prevê a legislação atual. 
não apenas às maiores capacidades de armazenamento dos produtos, mas também à localização das bases que, via de regra, foram instaladas em regiões próximas as unidades produtoras.

Diante deste cenário, no presente artigo avaliou-se o grau de poder de mercado das distribuidoras de gasolina $\mathrm{C}$ nas regiões brasileiras, no período de 2002 a 2008. A competição nos mercados de gasolina C no Brasil tem sido frequentemente estudada; veja, por exemplo, Nunes e Gomes (2005) e Pinto e Silva (2008). Entretanto, ainda são escassos os estudos dessa natureza com aplicações empíricas para este mercado no contexto dos modelos da NEIO.

$\mathrm{O}$ artigo está dividido em quatro seções, além desta introdução. $\mathrm{Na}$ segunda, apresenta-se o referencial teórico baseado no modelo proposto por Bresnahan (1982) e Lau (1982). Na terceira, descreve-se o modelo analítico, a partir da especificação do modelo econométrico, método de estimação, e, por fim, definem-se as variáveis e dados utilizados. Na quarta, analisam-se e discutem-se os resultados das estimativas do modelo. Na quinta, apresenta-se uma síntese conclusiva desse artigo e recomendações para pesquisas futuras.

\section{Modelo Teórico}

\subsection{A Teoria da Nova Organização Industrial Empírica: O Modelo de Bresnahan (1982)}

Os estudos da New Empirical Industrial Organization (NEIO) começaram a tomar forma a partir da década de 1980. O objetivo desses trabalhos era aferir o grau de poder de mercado por meio da identificação e estimação de um parâmetro de conduta, com modelos que admitem custos marginais não observáveis.

Segundo Bresnahan (1982), a identificação do parâmetro de conduta, que determina o grau de poder de mercado, está relacionada, especialmente, à capacidade de resposta dos preços às variações na elasticidade-preço da demanda e mudanças nos custos. Portanto, se a função demanda for rotacionada ao longo de seu eixo, ou seja, se houver uma alteração da elasticidade-preço da demanda, pode-se verificar se há ou não presença de poder de mercado por parte das firmas, através da identificação do parâmetro de conduta e da forma 
que a receita marginal assume. No caso de mercados competitivos, cuja regra de maximização de lucro por parte das empresas é a de $\mathrm{P}$ = Cmg, o preço de equilíbrio permaneceria inalterado, enquanto que na presença de poder de mercado, mudanças na elasticidade-preço da demanda modificam a decisão ótima de preços da firma. Assim, o parâmetro de conduta da firma pode ser identificado a partir do deslocamento e rotação da curva de demanda, conforme representado pela Figura 1 .

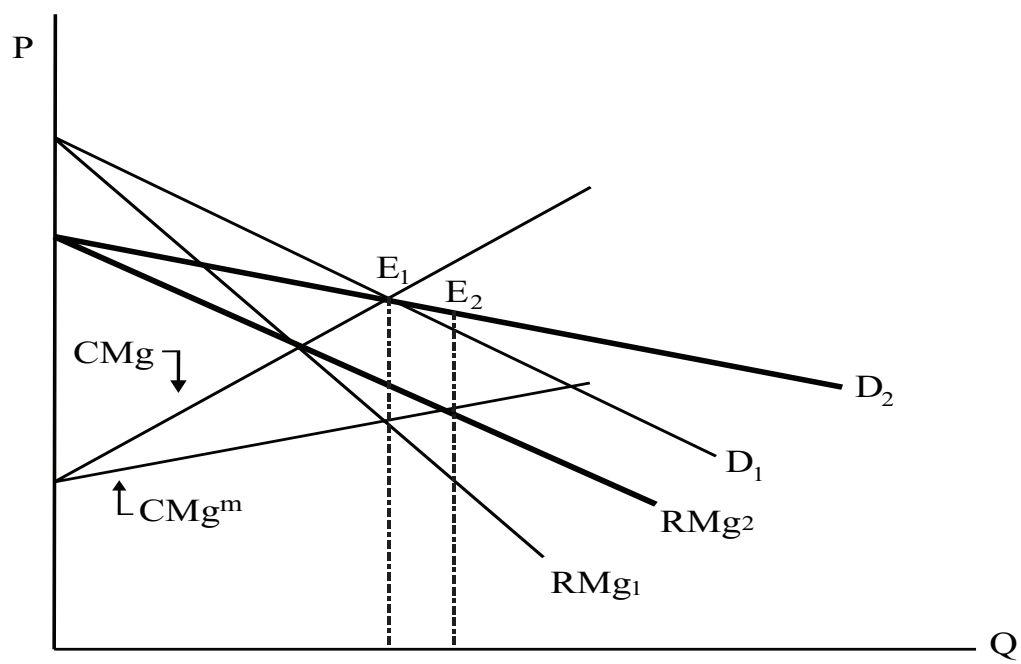

Figura 1 - Mudança na elasticidade-preço da demanda e a determinação do equilíbrio de mercado

Fonte: Bresnahan (1982).

Sejam $\mathrm{D}_{1}$ e $\mathrm{RMg}_{1}$ as funções lineares de demanda e receita marginal, iniciais, respectivamente. O custo marginal também é uma função linear, e pode ser representado por $\mathrm{CMg}^{\mathrm{c}}$, custo marginal em concorrência perfeita e $\mathrm{CMg}^{\mathrm{m}}$ em monopólio. Assim, $\mathrm{E}_{1}$ é o equilíbrio de quantidade seja para concorrência perfeita ou monopólio. A partir de uma rotação da curva de demanda $\left(D_{1}\right)$ ao longo do ponto $E_{1}$ tem-se $E_{2}$, o que modifica a curva de receita marginal de $\mathrm{RMg}_{1}$ para $\mathrm{RMg}_{2}$. $\mathrm{E}_{1}$ continua sendo o equilíbrio para concorrência perfeita, mas o equilíbrio para o caso de monopólio ou cartel perfeito encontra-se agora em $\mathrm{E}_{2}$. Se a curva de demanda somente se desloca, um novo ponto de equilíbrio seria encontrado, mas seria igual para ambos os casos. 
Portanto, Bresnahan (1982) desenvolveu um modelo que permite identificar o grau de poder de mercado, a partir da identificação de um parâmetro de conduta médio em oligopólios. O modelo proposto por Bresnahan (1982) e Lau (1982) tem preço e quantidade, determinados pela interseção da função de demanda e da relação de oferta. A função de demanda presume compradores tomadores de preços. Além disso, apresenta uma variável-chave que desloca e rotaciona a função de demanda. A relação de oferta é determinada a partir da regra de maximização de lucro, em que receita e custo se igualam na margem. A metodologia básica que permeia as análises da NEIO parte de uma estrutura de oligopólio para mensurar o grau de poder de mercado, incluindo variáveis endógenas observadas de maximização, considerando a função de demanda linear e a de custo marginal, conforme as expressões:

$$
\begin{aligned}
& Q=\alpha_{o}+\alpha_{1} P+\alpha_{2} y+\alpha_{3} P Z+\alpha_{4} Z \\
& C M g=\beta_{o}+\beta_{1} Q+\beta_{2} W
\end{aligned}
$$

Q é a quantidade, P é o preço, y é uma variável exógena, os parâmetros $\alpha_{i}$ são os coeficientes a serem estimados do lado da demanda e Z é uma variável exógena pelo lado da demanda. A característicachave desta variável $Z$ é que ela age interativamente com $P$, de forma que mudanças em $Z$ combinam elementos de deslocamento vertical e rotação na demanda, viabilizando a identificação do parâmetro de conduta, $\lambda$. Os parâmetros $\beta_{i}$ são os coeficientes a serem estimados do lado da relação de oferta. W é a variável exógena na função de oferta, e, CMg refere-se ao custo marginal das firmas.

Para derivar a relação de oferta, pressupõe-se uma receita marginal percebida genérica, que depende do parâmetro $\lambda$, dada por, $R M g=P+\lambda(\partial P / \partial Q) Q$. Para obter a função de demanda inversa, inverte-se a função de demanda (1):

$$
P=\frac{Q}{\left(\alpha_{1}+\alpha_{3} Z\right)}-\frac{\left(\alpha_{0}+\alpha_{2} y+\alpha_{4} Z\right)}{\left(\alpha_{1}+\alpha_{3} Z\right)}
$$

em que, $\frac{\partial P}{\partial Q}=\lambda \frac{1}{\left(\alpha_{1}+\alpha_{3} Z\right)}$ 
Igualando a receita marginal percebida ao custo marginal é possível obter a relação de oferta, que pode ser expressa conforme Equação (3):

$$
P=-\frac{\lambda}{\left(\alpha_{1}+\alpha_{3} Z\right)} Q+\beta_{0}+\beta_{1} Q+\beta_{2} W
$$

Considere, $Q^{*}=-\frac{Q}{\left(\alpha_{1}+\alpha_{3} Z\right)}$, assim, a Expressão (3) pode ser reescrita como:

$$
P=\lambda Q^{*}+\beta_{0}+\beta_{1} Q+\beta_{2} W
$$

Para identificar $\lambda$ e $\beta_{1}$ em (3'), $\alpha_{1}$ e $\alpha_{3}$ são tratados como conhecidos pela estimação da primeira função de demanda. Logo, $\lambda$ é identificado como o coeficiente de $\mathrm{Q}^{*}$. As expectativas teóricas a respeito do parâmetro de conduta pressupõem que, se as firmas se comportam como em competição perfeita, $\lambda=0$ e a Equação (3') se reduz à condição usual de $P=C M g$; se elas agirem de forma colusiva, (cartel perfeito), $\lambda=1$ e a maximização do lucro é semelhante a de um monopólio.

O modelo teórico desenvolvido por Bresnahan (1982) também é apresentado nos trabalhos de Karp e Perloff (1989), Deodhar and Sheldon (1996), Steen e Salvanes (1999), Hjalmarsson (2000), Nakane (2002) e Susanto (2006), dentre outros.

\section{Modelo Analítico}

\subsection{Especificação do Modelo Econométrico e Método de Estimação}

De acordo com Bresnahan (1982), as variáveis que deslocam a demanda podem ser a renda, o preço de um bem substituto e a tendência no tempo. Por outro lado, as variáveis deslocadoras da relação de oferta podem ser aquelas que incluem o preço dos insumos. A equação de demanda e a relação de oferta da distribuição de gasolina $\mathrm{C}$ nas regiões foram especificadas conforme as Expressões (4) e (5). 
Primeiramente estimou-se a equação de demanda e, na sequência, a relação de oferta. Nesta, obteve-se diretamente o parâmetro de conduta que foi construído a partir dos coeficientes estimados na equação de demanda, como descrito no modelo teórico. A especificação estática da equação de demanda é expressa conforme a Equação (4):

$$
Q_{g i}=\alpha_{0 i}+\alpha_{p g} P_{g i}+\alpha_{p a} P_{a}+\alpha_{d} D f l e x+\alpha_{y} Y+\alpha_{z} Z_{i}+\alpha_{p z} P_{g} Z_{i}+\sum_{j=1}^{12} \beta_{M} M_{j}+u_{t}
$$

em que, i é a região analisada, $Q_{g}$ são as vendas de gasolina $\mathrm{C}$ pelas distribuidoras, em metros cúbicos; $P_{g}$ é o preço médio da gasolina $\mathrm{C}$ praticados pelas distribuidoras, R $\$ /$ litro; $P_{a}$ é o preço médio do álcool hidratado nas distribuidoras, $\mathrm{R} \$ /$ litro; $D$ flex é a variável dummy, que representa a introdução da tecnologia flex no mercado automobilístico a partir de março de 2003, em que, $D$ flex $=1$, do mês de março de 2003 a dezembro de 2008 e, Dflex=0, nos demais meses; $Y$ é o índice de base fixa mensal sem ajuste sazonal da produção física industrial, utilizado como proxy da renda real; $Z$ é a quantidade de automóveis e comerciais leves vendidos no mercado atacadista interno que utilizam a gasolina como combustível, em unidades; $P_{g} Z$ é o produto entre $P_{g}$ e $Z$, sendo que $Z$ apresenta uma interdependência com $P_{g}$, de forma que se possa fazer uma distinção entre os pontos de equilíbrio competitivo e competição imperfeita; $\mathrm{M}$ representa as dummies sazonais; $\boldsymbol{u}_{t}$ é o termo de erro aleatório. A relação de oferta é especificada conforme a Equação (5):

$$
P_{g i}=\beta_{0 i}+\beta_{Q i} Q_{g i}+\beta_{W 1 i} W_{1 i}+\beta_{W 2 i} W_{2 i}+\sum_{i=1}^{12} \beta_{M} M_{j}+\psi \text { tend }+\lambda_{i} Q_{i t}^{*}+u_{i t}
$$

em que $W_{1 i}$ representa o preço médio da gasolina A praticado pelos produtores (refinarias, centrais petroquímicas e importadores) incluso os devidos impostos, em R $\$ /$ litro; $W_{2 i}$ é o preço médio do álcool

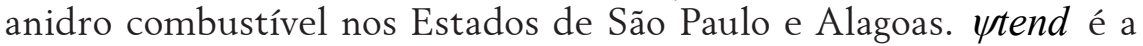
tendência linear introduzida nas relações de oferta.

Uma das principais críticas relacionadas às abordagens que seguem a metodologia de Bresnahan (1982) refere-se ao caráter estático dos trabalhos empíricos derivados desse modelo. Parte-se do pressuposto de que a abordagem estática não é eficiente para captar as interações estratégicas entre as firmas. Estas levam a um equilíbrio de longo prazo, representado por um parâmetro de conduta estável, que pode 
diferir daquele obtido para o curto prazo, que por sua vez, é ajustado pela conduta das empresas do setor. Assim, modelagens dinâmicas são alternativas mais consistentes e representam a melhor maneira de tratar o parâmetro de conduta, uma vez que captura o comportamento estratégico subjacente dos participantes do mercado. Diante desse contexto, no presente estudo, assim como no trabalho de Steen e Salvanes (1999), além da versão estática se estimou uma versão dinâmica do modelo de Bresnahan (1982).

Steen e Salvanes (1999) propuseram uma reformulação dinâmica para o modelo de Bresnahan (1982), a partir do mecanismo de correção de erros (MCE). Segundo esses autores, o modelo dinâmico é relevante, pois leva em consideração a dinâmica de curto prazo e também resolve o problema de inferência quando são utilizados dados não estacionários. Além disso, o fato de o modelo dinâmico incluir observações defasadas nas variáveis endógenas adiciona fatores dinâmicos como mudanças nos hábitos de consumo e choques nos custos para os produtores. Consequentemente, esses fatores tornam a utilização do modelo estático pouco eficiente, uma vez que modelos estáticos não são capazes de fornecer informações sobre um parâmetro de conduta de curto prazo distintas daquele de longo prazo.

Hjalmarsson (2000) propôs uma versão dinâmica do trabalho de Bresnahan (1982), um Modelo Autorregressivo de Defasagens Distribuídas (ADL), que representa uma alternativa ao modelo dinâmico sugerido por Steen e Salvanes (1999), pois permite que as estimativas sejam realizadas em um contexto de dados estacionários e integrados de ordens distintas. Portanto, é mais flexível quanto aos resultados dos testes de estacionariedade e cointegração. A estrutura de seu modelo segue uma reparametrização do ADL. ${ }^{2}$ Assim, as Equações (4) e (5) foram estimadas conforme um procedimento sequencial. Inicialmente, estimou-se um modelo geral, com o maior número de defasagens possível, e em cada etapa excluíram-se os coeficientes não significativos das variáveis defasadas, resultando em um modelo particular. O critério de Schwartz e a estatística $F$ devem ser usados para reduzir o modelo geral para o particular. A versão dinâmica requer a realização de testes para validar os resultados de sua estimação. Portanto, além dos testes de raiz unitária e cointegração,

2 A abordagem dinâmica requer a realização prévia de alguns testes a fim de se assegurar a validade de seus resultados, dentre os quais se destacam teste de raiz unitária e cointegração. Para maiores detalhes sobre estes testes, consultar Enders (1995) e Johansen e Juselius (1990). 
foram realizados testes de separabilidade. De acordo com o "teorema de impossibilidade" de Lau (1982), a identificação do grau de competição da indústria, conforme a abordagem da NEIO, é impossível se a função demanda inversa for separável em um vetor de variáveis exógenas $\mathrm{Z}$. Portanto, para que o grau de poder de mercado possa ser identificado na prática, o coeficiente da variável de interação, PZ, tem que ser estatisticamente diferente de zero.

As equações de demanda e as relações de oferta na versão dinâmica podem ser representadas pelas Expressões (6) e (7), respectivamente:

$Q_{t}=\alpha_{0}+\sum_{i=1}^{k} \gamma_{i} Q_{t-i}+\psi D f l e x+\sum_{j=1}^{12} \beta_{M} M_{j}+\sum_{i=0}^{k} \alpha_{y, i} Y_{t-i}+\sum_{i=0}^{k} \alpha_{Z, i} \Delta Z_{t-i} \sum_{i=0}^{K} \alpha_{P, i} P 1_{t-i}$

em que os parâmetros de longo prazo são dados por:

$$
\theta_{j}=\sum_{i=0}^{k} \alpha_{j, i} / 1-\sum_{i=1}^{k} \gamma_{i}, \text { e } j=P 1, Y, Z, P Z
$$

ou seja, o parâmetro $\theta_{p}$ mensura o impacto estacionário de longo prazo de $P_{t}$ em $Q_{t} ; 1-\sum_{i=1}^{k} \gamma_{i}$ é usualmente denotado como a velocidade de ajustamento e mensura quão rapidamente as firmas podem corrigir os erros das decisões passadas.

$$
\begin{aligned}
& \Delta P_{t}=\beta_{0}+\sum_{i=1}^{k} \phi_{i} \Delta P_{t-i}+\sum_{i=0}^{k} \beta_{Q, i} Q_{t-i}+\sum_{i=0}^{k} \beta_{W 1, i} W 1 a_{t-i}+\sum_{i=0}^{k} \beta_{W 2, i} \Delta W 2_{t-i}+ \\
& +\varphi \text { tend }+\sum_{j=1}^{\mathcal{L}} \beta_{M} M_{j}+\sum_{i=0}^{k} \lambda_{i} Q^{*}{ }_{t-i}+\Psi V 1_{t-1}
\end{aligned}
$$

em que,

$$
\Lambda=\sum_{i=0}^{k} \lambda_{i} / 1-\sum_{i=1}^{k} \phi_{i} ; \quad \xi_{Q}^{*}=\sum_{i=0}^{k} \beta_{Q, i} / 1-\sum_{i=1}^{k} \phi_{i} ; \xi_{W V}^{*}=\sum_{i=0}^{k} \beta_{W} / 1-\sum_{i=1}^{k} \phi_{i}
$$


$P 1$, é o vetor de cointegração entre as variáveis integradas de primeira ordem na função de demanda. $V 1$ é o vetor entre as variáveis integradas de ordem um na relação de oferta. De acordo com Vassilopoulos (2003), o coeficiente de $\Psi$ é o vetor de correção de erros.

O modelo sugerido por Hjalmarsson (2000) apresenta algumas particularidades: as equações de demanda e oferta incorporam os vetores de cointegração determinados a partir das variáveis integradas de ordem um I(1). A introdução desses vetores nas equações permite que todas as variáveis se tornem estacionárias. Por outro lado, na relação de oferta, como a variável dependente é integrada de ordem um, os autores utilizaram uma reparametrização do modelo ADL. ${ }^{3}$ Nesse caso, as variáveis I(1) são tomadas em sua primeira diferença e, um vetor de cointegração, $V 1_{t-1}$, formado pelos preços é introduzido na relação de oferta.

A modelagem econométrica da equação de demanda e a da relação de oferta determinam, simultaneamente, preço e quantidade de equilíbrio. A especificação dessas expressões leva à determinação de modelos econométricos com variáveis endógenas como explicativas. Nesse caso, a aplicação do método de Mínimos Quadrados Ordinários (MQO), conduz a estimativas viesadas e inconsistentes dos parâmetros do modelo. Se a variável preço se distribui independentemente de $\varepsilon_{t}$ na equação de demanda, e a variável quantidade, $\mathrm{Q}$, distribui-se independente na relação de oferta, o método MQO é recomendado. Se houver simultaneidade, o método dos Mínimos Quadrados em Dois Estágios (MQ2E) representa uma solução alternativa para se obter resultados consistentes e eficientes (Judge et al., 1988).

O método MQ2E trata cada uma das equações isoladamente, permitindo corrigir o problema da endogeneidade a partir das variáveis instrumentais. Pelo lado da demanda, os instrumentos podem ser as variáveis de custo deslocadoras da oferta, quantidade e preços defasados. Já na oferta além dessas duas últimas, podem ser utilizadas como instrumentos as variáveis deslocadoras da demanda conforme definidas anteriormente.

3 Para mais informações sobre esse modelo, ver Hjalmarsson (2000), Vassilopoulos (2003) e Bask et al. (2007). 
A presença da endogeneidade foi examinada a partir do teste de Wu-Hausman e a validade dos instrumentos foram testados a partir do teste de Sargan. ${ }^{4}$ A presença ou não de heterocedasticidade foi testada a partir do teste de Pagan-Hall, enquanto a autocorrelação foi verificada pelo teste de Cumby-Huizinga; por último, o teste Reset (Regression Specification Error Test) foi realizado para testar se a especificação linear das equações foi satisfatória para captar o relacionamento entre as variáveis. O software utilizado na estimação dos modelos foi o Stata 10.0.

\subsection{Variáveis e Fontes de Dados}

Neste artigo, a gasolina C foi escolhida previamente como produto relevante para representar o setor de distribuição de combustíveis líquidos devido às características do mercado que sugerem a possibilidade de exercício de poder de mercado. Sobre a dimensão geográfica, pelo fato de existirem distribuidoras atuando em todas as regiões do país, optou-se por realizar uma pesquisa desagregada em regiões. Também, baseou-se na análise realizada pelo Ato de Concentração n. ${ }^{\circ}$ 08012.002810/2000-74, de interesse das empresas Petrobrás Distribuidora S/A e Agip do Brasil Ltda., cuja dimensão geográfica para a atividade de distribuição de combustíveis foi definida como regional. Os dados utilizados neste artigo foram mensais, compreendendo o período de janeiro de 2002 a dezembro de 2008, portanto, 84 observações, e suas respectivas fontes foram:

As vendas de gasolina $\mathrm{C}$ pelas distribuidoras, em metros cúbicos, preços médios da gasolina $\mathrm{A}$ ao produtor ( $\mathrm{R} \$ /$ litro), preço médio da gasolina $\mathrm{C}(\mathrm{R} \$ /$ litro), preço médio do álcool hidratado ( $\mathrm{R} \$ /$ litro), os dois últimos, praticados pelas distribuidoras, foram todos obtidos junto à Agência Nacional de Petróleo, Gás Natural e Biocombustíveis - ANP. As séries de preços do álcool anidro combustível (R $\$ /$ litro) nas usinas e destilarias dos Estados de São Paulo e Alagoas ${ }^{5}$

4 O teste estatístico de Sargan (1964) tem uma distribuição $\chi^{2}$ (qui-quadrado) com $(p-h)$ graus de liberdade, em que p é o número de instrumentos e $\mathrm{h}$ o número de regressores. A hipótese nula do teste é a de que todos os instrumentos utilizados são válidos.

5 Em razão da indisponibilidade de dados dos preços do álcool anidro por Região, utilizaram-se os preços do Estado de São Paulo como representativos para o Centro-Oeste, Sul e Sudeste. Já os preços do Alagoas representaram o Norte e Nordeste. Uma vez que tais Estados são importantes produtores e comercializadores deste combustível, a utilização dessas séries como proxy para as regiões supracitadas não constitui um elemento impeditivo à realização da análise. 
foram obtidas junto ao Centro de Estudos Avançados em Economia Aplicada - CEPEA. A série referente às vendas de automóveis e comerciais leves que utilizam a gasolina como combustível, no mercado atacadista interno, é proveniente da Associação Nacional dos Fabricantes de Veículos Automotores - ANFAVEA. Devido a indisponibilidade de dados mensais de vendas de automóveis por tipo de combustível em nível regional, para todo o período em análise, utilizaram-se os dados do Brasil como proxy para as regiões brasileiras. Assim como no trabalho de Schunemann (2007), o índice de base fixa mensal sem ajuste sazonal da produção física industrial foi utilizado como proxy da renda. Esta variável foi obtida junto ao site do Instituto Brasileiro de Geografia e Estatística - IBGE.

\section{Análise e Discussão dos Resultados}

\subsection{Análise Estática do Grau de Poder de Mercado das Distribuidoras de Gasolina C}

Esta seção apresenta os resultados da estimação empírica do modelo, baseado em Bresnahan (1982), para os mercados regionais de distribuição de gasolina $\mathrm{C}$. As estimativas das equações de demanda e oferta de gasolina C são apresentadas nas Tabelas 1 e 2. Os resultados das dummies sazonais encontram-se no Apêndice, Tabelas 1A e $2 \mathrm{~A}$.

A quantidade demandada de gasolina $\mathrm{C}$ e o preço desse combustível foram instrumentalizados antes da estimação das equações de demanda e oferta. ${ }^{6}$ Sobre o ajuste do modelo, o $\mathrm{R}^{2}$ ajustado foi elevado, evidenciando que as variáveis independentes explicam em grande medida a variabilidade da variável dependente. Para testar a validade dos instrumentos utilizados, utilizou-se a estatística de Sargan. Os resultados desse teste não permitiram rejeitar a hipótese nula de que todos os instrumentos utilizados foram válidos. Os resultados para o teste Reset (Regression Specification Error Test), mostraram que a especificação linear das variáveis foi satisfatória para captar

6 Utilizaram-se como instrumentos, as variáveis explicativas das equações de oferta na equação de demanda e, variáveis explicativas da demanda nas equações de oferta; além disso, em alguns casos, as variáveis dependentes defasadas em um período, quando estas se revelaram instrumentos válidos pelo teste de Sargan. 
o relacionamento entre as variáveis. O teste de Hausman-WU sugeriu que a hipótese de que as variáveis dependentes na demanda e oferta, quantidade e preço, respectivamente, sejam endógenas não pôde ser rejeitada. Este resultado justifica a instrumentalização dessas variáveis para estimação por MQ2E. Os resultados do teste de Pagan-Hall não permitiram rejeitar a hipótese nula de resíduos homocedásticos, nas equações de oferta e demanda. Entretanto, pelo teste de Cumby-Huizinga verificou-se que embora a presença de autocorrelação residual nas equações de demanda tenha sido detectada apenas para o Centro-Oeste, de modo geral, foi um problema nas relações de oferta, exceto nas regiões Norte e Sul. Portanto, foi necessário incorporar um componente autorregressivo nessa equação para solucionar o problema.

Os resultados das estimativas da equação de demanda estão reportados na Tabela 1:

Tabela 1 - Estimativa da demanda de gasolina $C$ nas regiões brasileiras, por Mínimos Quadrados em Dois Estágios, formulação estática

\begin{tabular}{|c|c|c|c|c|c|}
\hline Variável & Sudeste & Sul & Nordeste & Norte & Centro - Oeste \\
\hline $\mathrm{Pg}$ & $\begin{array}{c}-38,550^{\text {ns }} \\
(85,879)\end{array}$ & $\begin{array}{c}-12,779^{\text {ns }} \\
(34,338)\end{array}$ & $\begin{array}{l}-9,618^{\text {ns }} \\
(32,715)\end{array}$ & $\begin{array}{c}-144,989^{\star \star *} \\
(17,298)\end{array}$ & $\begin{array}{l}-8,659^{\text {ns }} \\
(18,97)\end{array}$ \\
\hline $\mathrm{Pa}$ & $\begin{array}{l}77,038^{\star *} \\
(35,865)\end{array}$ & $\begin{array}{l}37,828^{* *} \\
(16,001)\end{array}$ & $\begin{array}{c}51,932^{\star \star \star} \\
(13,417)\end{array}$ & $\begin{array}{c}32,415^{\star \star \star} \\
(6,823)\end{array}$ & $\begin{array}{c}15,834^{\star \star} \\
(7,135)\end{array}$ \\
\hline dflex & $\begin{array}{c}-51,622^{\star \star \star} \\
(10,683)\end{array}$ & $\begin{array}{c}15,932^{\star \star \star} \\
(5,833)\end{array}$ & $\begin{array}{c}-14,463^{\star \star \star} \\
(4,303)\end{array}$ & $\begin{array}{l}-2,416^{\mathrm{ns}} \\
(1,803)\end{array}$ & $\begin{array}{c}8,047^{\star \star \star *} \\
(2,506)\end{array}$ \\
\hline$Y$ & $\begin{array}{c}2,469^{* * *} \\
(0,678)\end{array}$ & $\begin{array}{l}1,656^{\star * *} \\
(0,359)\end{array}$ & $\begin{array}{l}0,544^{*} \\
(0,291)\end{array}$ & $\begin{array}{c}0,594^{\star * *} \\
(0,109)\end{array}$ & $\begin{array}{c}0,767^{\star \star \star} \\
(0,153)\end{array}$ \\
\hline$Z$ & $\begin{array}{l}0,007^{\star \star \star *} \\
(0,002)\end{array}$ & $\begin{array}{c}0,002^{\star \star \star} \\
(0,001)\end{array}$ & $\begin{array}{c}0,004^{\star \star \star} \\
(0,001)\end{array}$ & $\begin{array}{c}-0,003^{* * *} \\
(6,31)\end{array}$ & $\begin{array}{l}0,001^{\star \star \star} \\
(0,001)\end{array}$ \\
\hline$P Z$ & $\begin{array}{c}-0,003^{\star \star \star} \\
(0,002)\end{array}$ & $\begin{array}{c}-0,001^{\star \star \star} \\
(0,0004)\end{array}$ & $\begin{array}{c}-0,001^{\star \star \star} \\
(0,003)\end{array}$ & $\begin{array}{c}0,003^{\star \star \star} \\
(0,001)\end{array}$ & $\begin{array}{c}-0,005^{\star \star} \\
(0,002)\end{array}$ \\
\hline Const. & $\begin{array}{l}737,75^{\star \star \star} \\
(224,686)\end{array}$ & $\begin{array}{c}195,494^{\star \star} \\
(94,648)\end{array}$ & $\begin{array}{c}112,716^{\text {ns }} \\
(78,635)\end{array}$ & $\begin{array}{c}348,250^{\star \star \star} \\
(40,615)\end{array}$ & $\begin{array}{l}2,195^{\text {ns }} \\
(52,631)\end{array}$ \\
\hline $\mathrm{AR}(1)$ & - & - & - & - & $\begin{array}{c}0,388^{* \star *} \\
(0,082)\end{array}$ \\
\hline $\mathrm{R}^{2}$ ajust. & 0,8200 & 0,7884 & 0,9151 & 0,9398 & 0,8501 \\
\hline Estatist. F & $17,01^{\star \star \star}$ & $18,20^{\star \star \star}$ & $37,14^{\star \star \star *}$ & $57,77^{\star \star \star}$ & $19,58^{\star \star \star}$ \\
\hline Teste Hausman & $4,106^{\star \star}$ & $5,440^{\star}$ & $4,808^{*}$ & $8,433^{\star \star \star}$ & $2,689^{*}$ \\
\hline Teste Autocor. & $0,12^{\text {ns }}$ & $0,89^{\text {ns }}$ & $1,39^{\text {ns }}$ & $2,08^{\text {ns }}$ & $4,756^{\text {ns }}$ \\
\hline Teste Heteroc. & $60,96^{\text {ns }}$ & $56,79^{\text {ns }}$ & $53,73^{\text {ns }}$ & $62,05^{\text {ns }}$ & $11,08^{\text {ns }}$ \\
\hline Teste Reset & $1,44^{\mathrm{ns}}$ & $1,41^{\mathrm{ns}}$ & $1,84^{\mathrm{ns}}$ & $0,36^{\text {ns }}$ & $1,17^{\mathrm{ns}}$ \\
\hline Teste Sargan ${ }^{+}$ & $0,330^{\text {ns }}$ & $4,343^{\text {ns }}$ & $4,049^{\text {ns }}$ & $1,001^{\mathrm{ns}}$ & $0,070^{\text {ns }}$ \\
\hline${ }^{+}$Instrumentos & variáveis & exógenas e & endógenas & defasadas. & \\
\hline
\end{tabular}

Fonte: Resultados da pesquisa.

Nota: $\left({ }^{* *}\right)$ indica significativo a $1 \%,\left({ }^{* *}\right)$; significativo a $5 \%,\left({ }^{*}\right)$ significativo a $10 \%$ e ns, não significativo.

Os valores entre parênteses referem-se aos desvios-padrão. 
No geral, os coeficientes apresentaram os sinais esperados, coerentes com a teoria econômica. A respeito da significância dos parâmetros estimados, a maioria deles se revelou estatisticamente significativos. Porém, o preço da gasolina $\mathrm{C}$ foi significativo apenas na região Norte do país, sugerindo que, pelo menos no curto prazo, ele não foi um fator relevante na determinação da demanda de gasolina $\mathrm{C}$ nas demais regiões.

Segundo Gomez (2009), as variações de preços nominais da gasolina são pequenas graças à política comercial adotada pela Petrobrás de não transferir para os preços internos as oscilações do mercado internacional. Consequentemente, têm-se longos períodos de preços estáveis, e estes são afetados apenas pelos efeitos da inflação ao consumidor, o que leva os testes de hipótese dos coeficientes desta variável não apresentarem significância no curto prazo.

O preço do álcool hidratado foi relevante para explicar a quantidade demandada de gasolina $\mathrm{C}$ em todas as regiões. Também, a proxy da renda e as vendas de automóveis e comerciais leves foram relevantes para explicar a quantidade demandada de gasolina $\mathrm{C}$ nesta região. Todas essas variáveis apresentaram-se positivamente correlacionadas com a quantidade demandada de gasolina C. A variável $D$ flex revelou-se relevante para explicar a variabilidade da demanda por gasolina na maioria das regiões, apresentando divergências quanto ao sinal.

A Tabela 2 apresenta os resultados dos coeficientes estimados para as relações de oferta de gasolina $\mathrm{C}$ e o parâmetro de conduta médio estimado nas regiões brasileiras. ${ }^{7}$

7 A variável tendência foi introduzida nas relações de oferta a fim de melhorar o ajustamento do modelo, de forma que os efeitos de outras variáveis não inseridas no modelo possam ser capturados. 
Tabela 2 - Estimativa das relações de oferta nas regiões brasileiras e o parâmetro de conduta, por Mínimos Quadrados em Dois Estágios, formulação estática

\begin{tabular}{|c|c|c|c|c|c|}
\hline Variável & Sudeste & Sul & Nordeste & Norte & Centro - Oeste \\
\hline$Q g$ & $\begin{array}{c}0,0002^{\text {ns }} \\
(0,001)\end{array}$ & $\begin{array}{l}0,003^{\star \star} \\
(0,001)\end{array}$ & $\begin{array}{l}0,001^{\star \star} \\
(0,001)\end{array}$ & $\begin{array}{c}-0,019^{\text {ns }} \\
(0,013)\end{array}$ & $\begin{array}{l}0,001^{*} \\
(0,001)\end{array}$ \\
\hline Pga & $\begin{array}{c}0,474^{\star \star *} \\
(0,613)\end{array}$ & $\begin{array}{c}1,800^{\star \star \star} \\
(0,191)\end{array}$ & $\begin{array}{c}1,002^{\star \star \star} \\
(0841)\end{array}$ & $\begin{array}{c}0,079^{\star \star *} \\
(0,189)\end{array}$ & $\begin{array}{c}0,626^{\star \star \star} \\
(0,066)\end{array}$ \\
\hline Paa & $\begin{array}{c}0,192^{\star \star \star} \\
(0,022)\end{array}$ & $\begin{array}{c}0,164^{* \star *} \\
(0,061)\end{array}$ & $\begin{array}{c}0,130^{\star \star \star} \\
(0,027)\end{array}$ & $\begin{array}{c}0,240^{\star * *} \\
(0,063)\end{array}$ & $\begin{array}{c}0,162^{\star \star \star} \\
(0,018)\end{array}$ \\
\hline tend. & $\begin{array}{c}-0,002^{\star \star \star} \\
(0,003)\end{array}$ & $\begin{array}{c}-0,007^{\star * *} \\
(0,002)\end{array}$ & $\begin{array}{c}-0,001^{\mathrm{ns}} \\
(0,001)\end{array}$ & $\begin{array}{c}-0,014^{\mathrm{ns}} \\
(0,105)\end{array}$ & $\begin{array}{l}-0,001^{*} \\
(0,001)\end{array}$ \\
\hline Const. & $\begin{array}{l}0,014^{\mathrm{ns}} \\
(0,205)\end{array}$ & $\begin{array}{c}-2,095^{\star * \star} \\
(0,804)\end{array}$ & $\begin{array}{c}-0,615^{\star \star} \\
(0,250)\end{array}$ & $\begin{array}{c}1,822^{\star \star \star} \\
(0,695)\end{array}$ & $\begin{array}{c}-0,101^{\mathrm{ns}} \\
(0,134)\end{array}$ \\
\hline$\hat{\lambda}_{i}$ & $\begin{array}{c}0,011^{\star \star \star} \\
(0,003)\end{array}$ & $\begin{array}{c}0,021^{* *} \\
(0,009)\end{array}$ & $\begin{array}{l}0,004^{\star} \\
(0,002)\end{array}$ & $\begin{array}{l}0,302^{n s} \\
(0,268)\end{array}$ & $\begin{array}{l}0,006^{* *} \\
(0,003)\end{array}$ \\
\hline $\operatorname{AR}(1)$ & $\begin{array}{c}0,481^{\star \star \star} \\
(0,041)\end{array}$ & - & $\begin{array}{c}0,392^{\star \star \star} \\
(0,043)\end{array}$ & - & $\begin{array}{c}0,454^{\star * *} \\
(0,038)\end{array}$ \\
\hline $\mathrm{R}^{2}$ ajust. & 0,9597 & 0,8096 & 0,9762 & 0,7988 & 0,9714 \\
\hline Estatist. F & $88,56^{\star \star \star}$ & $20,17^{\star \star *}$ & 132,09 & $12,44^{\star \star *}$ & $126,85^{\star \star \star}$ \\
\hline Teste Hausman & $6,003^{*}$ & $24,225^{\star * *}$ & $3,025^{\star}$ & $5,768^{\star \star \star}$ & $23,157^{\star \star \star}$ \\
\hline Teste Autocor. & $1,46^{\text {ns }}$ & $1,13^{\mathrm{ns}}$ & $5,91^{\mathrm{ns}}$ & $0,43^{\text {ns }}$ & $4,663^{\text {ns }}$ \\
\hline Teste Heteroc. & $21,25^{\text {ns }}$ & $2,58^{\text {ns }}$ & $15,35^{\text {ns }}$ & $0,30^{\text {ns }}$ & $9,872^{\text {ns }}$ \\
\hline Teste Reset & $2,12^{\text {ns }}$ & $1,85^{\mathrm{ns}}$ & $2,08^{n s}$ & $0,46^{\text {ns }}$ & $1,04^{\mathrm{ns}}$ \\
\hline Teste Sargan $^{+}$ & $4,783^{\text {ns }}$ & $6,221^{\text {ns }}$ & $5,376^{\text {ns }}$ & $0,387^{\mathrm{ns}}$ & $6,070^{\text {ns }}$ \\
\hline 'Instrumentos: & variáveis & exógenas e & endógenas & defasadas. & \\
\hline
\end{tabular}

Fonte: Resultados da pesquisa.

Nota: Utilizou-se o nível de significância de até 5\%, para os testes Reset e Sargan.

$\left({ }^{* * *}\right)$ indica significativo a $1 \%,\left({ }^{* *}\right)$ significativo a $5 \%,\left({ }^{*}\right)$ significativo a $10 \%$, ns, não significativo. Os valores entre parênteses referem-se aos desvios-padrão.

A relação de oferta depende dos coeficientes estimados na equação de demanda. Portanto, de posse dos resultados desses coeficientes, estimaram-se as relações de oferta.

São nas distribuidoras que ocorrem a mistura da gasolina $\mathrm{A}$ e do álcool anidro resultando na gasolina C. Portanto, as variáveis deslocadoras da relação de oferta foram os preços da gasolina A e do álcool anidro praticados nas refinarias, centrais petroquímicas e usinas. Nos preços da gasolina A já estão embutidos os devidos impostos, de modo que ambos os preços explicam, em grande medida, os custos de produção da gasolina C.

Os resultados obtidos nas relações de oferta foram consistentes com a teoria econômica. A maioria dos coeficientes apresentou-se, estatis- 
ticamente significativo. A variável tendência foi incluída nas relações de oferta para captar os efeitos de outras variáveis não inseridas no modelo. Esta se mostrou significativa e negativamente relacionada com o preço de mercado, exceto para o Norte e Nordeste em que se apresentou irrelevante.

Sobre as variáveis de custos, preços do álcool anidro e gasolina A, verificou-se que ambas se apresentaram positivamente correlacionadas com o preço da gasolina C. Ressalta-se que o preço da gasolina C é influenciado pelas variações no preço do álcool anidro. ${ }^{8}$

A respeito do grau de competição existente entre as distribuidoras de gasolina $\mathrm{C}$ nas regiões brasileiras, verifica-se que os parâmetros estimados, $\lambda_{i}$, revelaram-se baixos, evidenciando que as empresas distribuidoras de gasolina $\mathrm{C}$ não possuem poder de mercado conjunto, ou seja, não atuam de forma colusiva. Por outro lado, exceto na região Norte, em que o parâmetro de conduta revelou-se estatisticamente não significativo, a hipótese de que as empresas ajam como tomadoras de preços foi rejeitada.

Portanto, com base nos resultados obtidos pela aplicação do modelo estático de Bresnahan (1982) pode-se concluir que as empresas localizadas em tais regiões não exerceram poder de mercado expressivo no período analisado. A princípio, esperava-se que houvesse um elevado grau de poder de mercado por parte das distribuidoras de gasolina $\mathrm{C}$ que atuam nas regiões brasileiras, em virtude das características que prevalecem nesses mercados geográficos. Entretanto, possivelmente, o grau de concentração setorial verificado nas regiões brasileiras pode ser explicado pela elevada eficiência das grandes distribuidoras, bem como pela necessidade de elevados investimentos em capital. A respeito da conduta das empresas, é importante ressaltar que a Agência Reguladora, a ANP, juntamente com os órgãos de defesa da concorrência, podem estar sendo efetivos no sentido de impedir um comportamento colusivo. A ANP comunica todo o indício de prática anticompetitiva aos órgãos do Sistema Brasileiro de Defesa de Concorrência (SBDC) para que estes tomem as providências legais.

8 A gasolina C é composta pela mistura da gasolina A com o álcool anidro. A proporção de álcool anidro nessa mistura é determinada pelo Conselho Interministerial do Açúcar e do Álcool (CIMA), podendo variar entre 20\% e 25\%, através de Resoluções. 
Apesar de sólida base teórica, é importante ressaltar que existem problemas de implementação prática com o modelo estático formulado por Bresnahan-Lau (1982). Conforme enfatiza Salvo (2008), a principal fragilidade do modelo está nas hipóteses adotadas e não testadas, ao se definir a equação de precificação (7). A formulação desenvolvida por estes autores, embora tenha como objetivo modelar as interações dinâmicas existentes entre os agentes (ação e reação entre firmas) utiliza para tal uma estrutura estática. Em situações em que os agentes se comportam de forma estratégica, o autor mostra que se pode cometer o erro tipo II, ou seja, deixa-se de rejeitar a hipótese nula de concorrência perfeita contra a hipótese verdadeira de cartel. Isso exige muita cautela na interpretação dos resultados, quando o valor de $\theta$ é próximo de zero.

Para Sexton e Zhang (2000), o modelo analisa o comportamento das firmas em um mercado de competição imperfeita onde as empresas reconhecem que suas ações podem influenciar o comportamento das outras. Assim, a principal crítica relacionada ao modelo estático é de que este não é eficiente em captar as interações estratégicas entre as empresas. Consequentemente, formulações dinâmicas consistem em uma alternativa plausível, sendo a melhor maneira de tratar o parâmetro de conduta, pois captura o comportamento estratégico subjacente dos participantes do mercado. Salvo (2008) apresenta uma extensão do modelo de Bresnahan-Lau para a situação onde há possibilidade de importações, com aplicação à indústria brasileira de cimento.

Nesse contexto uma abordagem dinâmica desse modelo deve ser utilizada a fim de superar estas limitações.

\subsection{Análise Dinâmica do Grau de Poder de Mercado das Distribuido- ras de Gasolina $C$}

Nesta seção são apresentados os resultados das estimativas do modelo dinâmico. Conforme salientado anteriormente, optou-se por estimar também uma versão dinâmica do modelo de Bresnahan (1982), pois este representa uma alternativa mais consistente e é a melhor maneira de tratar o parâmetro de conduta, uma vez que capta o comportamento estratégico subjacente dos participantes do mercado. 
O modelo dinâmico requer a realização prévia de alguns testes para assegurar a validade de seus resultados. Portanto, além das estimativas das demandas e ofertas regionais, realizaram-se os testes de raiz unitária, e, por último, separabilidade na variável que desloca e rotaciona a curva de demanda $\mathrm{PZ}$. Todos esses resultados são apresentados no Apêndice, Tabelas 3A a 6A. O teste de raiz unitária Dickey-Fuller Aumentado (ADF) foi realizado segundo o procedimento sequencial. Para tanto, empregou-se o número de defasagens que minimizou o Critério de Schwarz. Como estes apontaram para a presença de algumas variáveis estacionárias em nível e outras na primeira diferença, optou-se pela realização da análise de cointegração apenas entre as variáveis não estacionárias. Os resultados dos testes do Traço e do Máximo Autovalor, realizados para o conjunto de variáveis das equações de demanda, indicaram que a hipótese nula de que não há cointegração entre as séries $\mathrm{Pg}, \mathrm{Pa}$ e $\mathrm{PZ}$, foi rejeitada, a $1 \%$ e 5\% de significância. Existe uma relação de cointegração entre as séries Pg, Pa e PZ nas equações de demanda. Nas equações de oferta, os testes indicaram que a hipótese nula de que não há cointegração entre as séries preço da gasolina $\mathrm{C}$ e da gasolina $\mathrm{A}$ e álcool anidro, na região Sudeste foi rejeitada a $1 \%$ de significância; e, entre os preços da gasolina $\mathrm{C}$ e do álcool anidro nas demais regióes, foi rejeitada a $5 \%$ de significância. Já a hipótese nula de existência de uma relação de cointegração não pode ser rejeitada.

A partir do teste de separabilidade procurou-se assegurar se é possível identificar o grau de poder de mercado por meio da estimação do parâmetro de conduta médio. Como os testes do traço e do máximo autovalor indicaram a existência de apenas uma única relação de cointegração, testou-se a hipótese de que o coeficiente da variável $\mathrm{PZ}$, para todas as regiões, é zero apenas neste vetor. O teste de separabilidade evidenciou que a hipótese nula de que $\alpha_{p z}=0$ foi rejeitada para todos os mercados geográficos, a um nível de $1 \%$ de significância, sugerindo que PZ pode ser utilizada para identificar o grau de poder de mercado, $\lambda$.

No modelo dinâmico as equações foram estimadas conforme o procedimento sequencial. Inicialmente, estimou-se um modelo geral, com o maior número de defasagens possível, e em cada etapa excluíram-se os coeficientes não significativos das variáveis defasadas, resultando em um modelo particular. Iniciou-se com oito defasagens e o critério de Schwartz e a estatística F foram usados para reduzir 
o modelo geral para o particular. Nas equações de demanda, a variável vendas de automóveis e comerciais leves movidos à gasolina foi utilizada na primeira diferença, pois a inclusão dela no vetor de cointegração gerou resultados com sinais teoricamente inconsistentes.

As Tabelas 4 a 6 reportam os resultados das estimativas das equações de demanda e ofertas do modelo dinâmico mais parcimonioso. No geral, o modelo revelou-se bem ajustado, o $\mathrm{R}^{2}$ apresentou um valor elevado, sugerindo que as variáveis independentes explicam, em grande medida, a variabilidade da variável dependente.

Os resultados do teste de Sargan não permitiram rejeitar a hipótese nula de que todos os instrumentos utilizados foram válidos. Conforme o teste Reset (Regression Specification Error Test), a especificação linear das variáveis foi satisfatória para captar o relacionamento entre as variáveis. Os resultados do teste de Pagan-Hall não permitiram rejeitar a hipótese nula de resíduos homocedásticos, nas equações de oferta e demanda. Também, o teste de Cumby-Huizinga evidenciou ausência de autocorrelação nos resíduos, sugerindo que os modelos foram bem formulados.

Inicialmente, o modelo geral foi estimado por meio do método de MQ2E. Porém, em alguma etapa do processo de exclusão de variáveis não significativas, a variável dependente revelou-se exógena pelo teste de Hausman, exceto para as regiões Norte e Centro-Oeste, na equação de demanda e região Nordeste na relação de oferta.

Nas equações de demanda, diversas defasagens incluídas no modelo não se revelaram estatisticamente significativas, sendo necessário excluí-las, Tabela 3. 
Tabela 3 - Estimativa dos coeficientes das funções de demanda do modelo dinâmico

\begin{tabular}{|c|c|c|c|c|c|}
\hline Variável & Sudeste & Sul & Nordeste & Norte & Centro-Oeste \\
\hline$P g_{t}$ & - & $\begin{array}{c}-27,519^{\star \star \star} \\
(14,863)\end{array}$ & - & $\begin{array}{l}-7,834^{*} \\
(4,725)\end{array}$ & $\begin{array}{c}-22,261^{\star \star \star} \\
(6,608)\end{array}$ \\
\hline$Q_{t-1}$ & $\begin{array}{c}0,399^{\star \star \star} \\
(0,131)\end{array}$ & - & $\begin{array}{c}0,560^{\star \star \star} \\
(0,108)\end{array}$ & - & $\begin{array}{c}0,543^{\star \star \star} \\
(0,102)\end{array}$ \\
\hline$Q_{t-3}$ & - & $\begin{array}{l}0,470^{* \star \star} \\
(0,115)\end{array}$ & - & - & $\begin{array}{l}0,387^{* *} \\
(0,092)\end{array}$ \\
\hline$Q_{t-4}$ & - & - & $\begin{array}{l}0,314^{* *} \\
(0,126)\end{array}$ & $\begin{array}{c}0,343^{\star \star *} \\
(0,081)\end{array}$ & - \\
\hline$Q_{t-5}$ & - & $\begin{array}{c}0,293^{\star * *} \\
(0,111)\end{array}$ & - & - & - \\
\hline$Q_{t-6}$ & - & $\begin{array}{c}0,224^{\star \star \star} \\
(0,120)\end{array}$ & - & - & - \\
\hline Dflex & $\begin{array}{l}-7,481^{\text {ns }} \\
(16,150)\end{array}$ & $\begin{array}{c}25,683^{\star * *} \\
(8,252)\end{array}$ & $\begin{array}{l}7,856^{\star \star} \\
(3,813)\end{array}$ & $\begin{array}{c}7,878^{\star \star \star} \\
(2,311)\end{array}$ & $\begin{array}{l}9,604^{* *} \\
(4,201)\end{array}$ \\
\hline$Y_{t}$ & $\begin{array}{c}4,467^{\star \star \star} \\
(1,020)\end{array}$ & - & $\begin{array}{c}1,456^{\star \star \star} \\
(0,319)\end{array}$ & $\begin{array}{l}0,325^{\star \star \star} \\
(0,102)\end{array}$ & $\begin{array}{l}0,998^{\star \star} \\
(0,192)\end{array}$ \\
\hline$Y_{t-1}$ & $\begin{array}{c}-4,463^{\star \star \star} \\
(1,580)\end{array}$ & - & $\begin{array}{c}-1,684^{* \star *} \\
(0,498)\end{array}$ & $\begin{array}{c}-0,312^{\star \star *} \\
(0,142)\end{array}$ & $\begin{array}{c}-1,198^{\star \star \star *} \\
(0,270)\end{array}$ \\
\hline$Y_{t-3}$ & $\begin{array}{c}2,604^{\star \star \star} \\
(1,127)\end{array}$ & - & $\begin{array}{c}2,382^{* \star \star} \\
(0,359)\end{array}$ & $\begin{array}{c}0,886^{\star \star *} \\
(0,135)\end{array}$ & - \\
\hline$Y_{t-4}$ & - & - & $\begin{array}{c}-1,799^{* *} \\
(0,488)\end{array}$ & - & - \\
\hline$Y_{t-7}$ & - & - & - & - & $\begin{array}{c}0,703^{\star \star \star *} \\
(0,225)\end{array}$ \\
\hline$Y_{t-9}$ & - & - & - & $\begin{array}{c}0,388^{\star \star \star} \\
(0,141)\end{array}$ & \\
\hline$\Delta v a c l$ & $\begin{array}{l}0,001^{*} \\
(0,001)\end{array}$ & - & - & $\cdot$ & - \\
\hline$\Delta v a c l_{t-1}$ & - & - & - & $\begin{array}{c}0,0001^{* * *} \\
(0,0001)\end{array}$ & - \\
\hline$P 1$ & - & $\cdot$ & $\begin{array}{c}-61,338^{* * \star} \\
(21,596)\end{array}$ & - & - \\
\hline$P 1_{t-1}$ & - & $\begin{array}{l}-60,542 \\
(26,935)\end{array}$ & - & $\begin{array}{c}-24,516^{* \star \star} \\
(6,591)\end{array}$ & - \\
\hline$P 1_{t-7}$ & - & - & - & $\begin{array}{c}-10,643^{* *} \\
(5,119)\end{array}$ & $\begin{array}{c}-43,293^{* \star *} \\
(15,118)\end{array}$ \\
\hline$P 1_{t-8}$ & $\begin{array}{c}-91,162^{\star \star *} \\
(49,395)\end{array}$ & - & - & - & $\begin{array}{l}28,432^{*} \\
(14,385)\end{array}$ \\
\hline Const. & $\begin{array}{c}303,648^{\star \star \star} \\
(122,286)\end{array}$ & $\begin{array}{c}125,700^{* *} \\
(48,672)\end{array}$ & $\begin{array}{l}57,543^{*} \\
(33,672)\end{array}$ & $\begin{array}{c}-8,054^{\text {ns }} \\
(17,219) \\
\end{array}$ & $\begin{array}{c}0,266^{\text {ns }} \\
(14,751)\end{array}$ \\
\hline$\overline{R^{2}}$ & 0,7873 & 0,8342 & 0,9170 & 0,9705 & 0,8737 \\
\hline Estatist. F & 16,43 & 17,76 & 46,92 & 81,60 & 18,98 \\
\hline \multicolumn{6}{|l|}{ Testes } \\
\hline Hausman & - & - & - & $5,916^{\star \star \star}$ & $3,414^{*}$ \\
\hline Autocor. & $0,132^{\text {ns }}$ & $0,545^{\mathrm{ns}}$ & $1,568^{\text {ns }}$ & $1,223^{\text {ns }}$ & $0,297^{\text {ns }}$ \\
\hline Heteroc. & $2,42^{\text {ns }}$ & $3,01^{\text {ns }}$ & $0,08^{\text {ns }}$ & $30,112^{\text {ns }}$ & $18,002^{\text {ns }}$ \\
\hline Reset & $1,71^{\text {ns }}$ & $0,71^{\mathrm{ns}}$ & $4,28^{\text {ns }}$ & $11,36^{\text {ns }}$ & $1,67^{\text {ns }}$ \\
\hline Sargan+ & - & - & - & $0,819^{\text {ns }}$ & $1,795^{\text {ns }}$ \\
\hline
\end{tabular}

Fonte: Resultados da pesquisa.

$\left({ }^{* * *}\right)$ significativo a $1 \%,\left({ }^{* *}\right)$ significativo a $5 \%,\left({ }^{*}\right)$ significativo a $10 \% \mathrm{e}^{\text {ns }}$, não significativo. Os valores entre parênteses referem-se aos desvios-padrão.

A existência de vetores $\mathrm{Pl}$, contemporâneos e/ou defasados, estatisticamente significativos, é relevante, pois, de acordo com o Teorema da Impossibilidade de Lau (1982), o poder de mercado é identificado somente se a função de demanda não for separável no parâmetro de interação. De acordo com Hjalmarsson (2000), para que a variável de interação seja significativa é suficiente que o vetor Pl seja estatis- 
ticamente significante. Como o vetor de cointegração, na estrutura de Johansen, é determinado pelas variáveis, preços da gasolina C, álcool hidratado e a variável de interação $\mathrm{PZ}$, a exclusão de uma delas determinaria a inexistência do vetor. A significância dos coeficientes das variáveis no longo prazo pode ser provada pelo teste de separabilidade. As estimativas das soluções estáticas de longo prazo encontram-se na Tabela 4.

Tabela 4 - Coeficientes de longo prazo da função de demanda do modelo dinâmico

Soma das estimativas dos componentes individuais de Pl

\begin{tabular}{lccccc}
\hline Variável & Sudeste & Sul & Nordeste & Norte & Centro-Oeste \\
\hline$P g_{t}$ & - & - & $-61,339$ & - & - \\
\hline$P a_{t}$ & - & - & 37,488 & - & - \\
\hline$P Z_{t}$ & - & - & $-0,0002$ & - & - \\
\hline$P g_{t-1}$ & - & $-60,542$ & - & $-24,516$ & - \\
\hline$P a_{t-1}$ & - & 41,018 & - & 6,279 & - \\
\hline$P Z_{t-1}$ & - & $-0,0001$ & - & 0,00007 & $-10,643$ \\
\hline$P g_{t-7}$ & - & - & - & 2,726 & 17,530 \\
\hline$P a_{t-7}$ & - & - & - & 0,00003 & $-0,0001$ \\
\hline$P Z_{t-7}$ & - & - & - & - & 28,432 \\
\hline$P g_{t-8}$ & $-91,162$ & - & - & - & $-11,513$ \\
\hline$P a_{t-8}$ & 66,956 & - & - & - & 8,330 \\
\hline$P Z_{t-8}$ & $-0,00007$ & - & - & \\
\hline
\end{tabular}

Solução estática de longo prazo

\begin{tabular}{|c|c|c|c|c|c|}
\hline Constante & $\begin{array}{l}504,980^{\star *} \\
(235,888)\end{array}$ & $\begin{array}{c}9742,436^{\star \star \star} \\
(1956,14)\end{array}$ & $\begin{array}{c}457,949^{\star \star \star} \\
(90,086)\end{array}$ & $\begin{array}{c}-12,251^{\star \star \star} \\
(0,240)\end{array}$ & $\begin{array}{l}3,840^{\text {nS }} \\
(29,552)\end{array}$ \\
\hline$P g_{t}$ & - & $\begin{array}{l}-2132,85^{\star \star} \\
(440,036)\end{array}$ & - & $\begin{array}{c}-11,923^{\mathrm{ns}} \\
(14,20)\end{array}$ & $\begin{array}{c}-322,238^{\star * \star} \\
(48,91)\end{array}$ \\
\hline$Y_{t}$ & $\begin{array}{c}4,339^{\text {ns }} \\
(4,59)\end{array}$ & - & $\begin{array}{c}2,902^{\star \star \star} \\
(1,02)\end{array}$ & $\begin{array}{c}2,000^{\star \star \star} \\
(0,83)\end{array}$ & $\begin{array}{c}7,286^{\star \star \star} \\
(1,14)\end{array}$ \\
\hline$\Delta v a c l$ & $\begin{array}{l}0,00150^{* *} \\
\left(5,9 \times 10^{-4}\right)\end{array}$ & - & - & $\begin{array}{c}0,0018^{\star * *} \\
\left(5,25 \times 10^{-4}\right)\end{array}$ & - \\
\hline D1 & $\begin{array}{c}-151,607^{\star \star \star} \\
(137,48)\end{array}$ & $\begin{array}{c}-4692,296^{\star \star *} \\
(4,93)\end{array}$ & $\begin{array}{c}-488,156^{\star * \star} \\
(104,95)\end{array}$ & $\begin{array}{c}-53,478^{\star} \\
(28,54)\end{array}$ & $\begin{array}{c}-215,13^{\star \star *} \\
(43,07)\end{array}$ \\
\hline
\end{tabular}

Componentes individuais de Pl no longo prazo

\begin{tabular}{cccccc}
\hline$\left(\theta_{p g}\right)$ & $-151,607$ & $-4692,296$ & $-488,156$ & $-53,478$ & $-215,131$ \\
\hline$\left(\theta_{p a}\right)$ & 111,350 & 3179,077 & 298,342 & 13,697 & 87,111 \\
\hline$\left(\theta_{p z}\right)$ & $-0,000128$ & $-0,0075$ & $-0,0013$ & $-0,0001$ & $-0,0006$ \\
\hline
\end{tabular}

Fonte: Resultados da pesquisa.

$\left({ }^{* * *}\right)$ indica significativo a $1 \%,\left({ }^{* *}\right)$ indica significativo a $5 \%,\left({ }^{*}\right)$ indica significativo a $10 \%$, ns, não significativo. Os valores entre parênteses referem-se aos desvios - padrão, que foram calculados a partir da transformação de Bardsen (1989). 
A variável preço mostrou-se relevante para explicar a demanda por gasolina C, apenas nas regiões Sul e Centro-Oeste. No Sudeste e Nordeste, a variável preço não se mostrou relevante para explicar a demanda por gasolina C; desse modo, foi necessário excluí-la da solução de longo prazo. Por outro lado, no Nordeste, Norte e CentroOeste, a demanda por gasolina $\mathrm{C}$ se revelou positivamente correlacionada com a renda para a solução estática de longo prazo. Por último, os coeficientes dos vetores de cointegração, $\mathrm{Pl}$, apresentaram sinais consistentes para a teoria econômica. Como consequência, seus componentes individuais de longo prazo também apresentaram sinais coerentes.

A Tabela 5 apresenta os resultados para as relações de oferta. O modelo geral foi estimado inicialmente por meio do método de MQ2E. Exceto para o Nordeste, as ofertas do modelo mais parcimonioso foram estimadas pelo método de $\mathrm{MQO}$, pois em alguma etapa do processo de exclusão de variáveis não significativas, o teste de Hausman apontou que a variável dependente tinha se revelado exógena.

Tabela 5 - Estimativa dos Coeficientes das Relações de Oferta do Modelo Dinâmico

\begin{tabular}{|c|c|c|c|c|c|}
\hline Variável & Sudeste & Sul & Nordeste & Norte & Centro-Oeste \\
\hline$\Delta P g_{t-1}$ & - & - & - & $\begin{array}{c}-0,243^{* * *} \\
(0,08)\end{array}$ & - \\
\hline$\Delta P g_{t-3}$ & - & - & - & $\begin{array}{c}-0,242^{* * *} \\
(0,074)\end{array}$ & - \\
\hline$\Delta P g_{t-4}$ & - & - & - & $\begin{array}{c}-0,166^{* * *} \\
(0,079)\end{array}$ & - \\
\hline$\Delta P g_{t-5}$ & - & - & - & $\begin{array}{c}-0,252^{* * *} \\
(0,068)\end{array}$ & - \\
\hline$\Delta P g_{t-6}$ & - & - & - & $\begin{array}{c}-0,165^{\star \star *} \\
(0,069)\end{array}$ & - \\
\hline$\Delta P g_{t-7}$ & - & - & - & $\begin{array}{l}-0,120^{* *} \\
(0,053)\end{array}$ & - \\
\hline$Q_{t}$ & . & $\begin{array}{l}0,001^{\star *} \\
(0,0004)\end{array}$ & $\begin{array}{l}0,001^{\star *} \\
(0,0005)\end{array}$ & - & - \\
\hline$Q_{t-3}$ & $\begin{array}{c}0,0002^{\star \star \star} \\
(0,0001)\end{array}$ & - & - & - & - \\
\hline$Q_{t-4}$ & - & - & - & - & $\begin{array}{l}0,002^{\star \star \star} \\
(0,001)\end{array}$ \\
\hline$Q_{t-5}$ & - & - & $\begin{array}{c}-0,0003^{* *} \\
(0,0001)\end{array}$ & - & - \\
\hline$Q_{t-7}$ & - & - & - & $\begin{array}{l}0,002^{* * *} \\
(0,001)\end{array}$ & \\
\hline$Q_{t-8}$ & - & - & & - & $\begin{array}{l}-0,001^{\star \star \star} \\
(0,0004)\end{array}$ \\
\hline
\end{tabular}


(Continuação)

\begin{tabular}{|c|c|c|c|c|c|}
\hline Variável & Sudeste & Sul & Nordeste & Norte & Centro-Oeste \\
\hline$P g a$ & - & $\begin{array}{c}1,202^{\star \star \star} \\
(0,094)\end{array}$ & $\begin{array}{c}1,192^{\star \star *} \\
(0,083)\end{array}$ & $\begin{array}{c}0,700^{* * *} \\
(0,057)\end{array}$ & $\begin{array}{c}0,816^{* \star *} \\
(0,078)\end{array}$ \\
\hline$\Delta P g a$ & $\begin{array}{c}0,582^{\star \star \star} \\
(0,074)\end{array}$ & - & - & - & \\
\hline$P g a_{t-1}$ & - & $\begin{array}{c}1,201^{\star \star *} \\
(0,085)\end{array}$ & $\begin{array}{c}-0,698^{\star * \star} \\
(0,119)\end{array}$ & - & $\begin{array}{c}-0,777^{\star * *} \\
(0,074)\end{array}$ \\
\hline$\Delta P g a_{t-1}$ & $\begin{array}{c}0,284^{* \star \star} \\
(0,084)\end{array}$ & - & - & - & \\
\hline$P g a_{t-2}$ & - & - & $\begin{array}{c}-0,392^{* * *} \\
(0,078)\end{array}$ & $\begin{array}{c}-0,443^{\star * \star} \\
(0,070)\end{array}$ & - \\
\hline$P g a_{t-8}$ & - & - & - & $\begin{array}{c}-0,243^{\star * *} \\
(0,048)\end{array}$ & \\
\hline$\triangle P a a$ & - & $\begin{array}{c}0,187^{\star \star \star} \\
(0,029)\end{array}$ & $\begin{array}{c}0,146^{\star \star *} \\
(0,028)\end{array}$ & $\begin{array}{l}0,079^{\star *} \\
(0,307)\end{array}$ & $\begin{array}{c}0,139^{* \star *} \\
(0,023)\end{array}$ \\
\hline$\Delta P a a_{t-1}$ & $\begin{array}{l}0,084^{\star *} \\
(0,039) \\
\end{array}$ & - & - & - & $\begin{array}{c}0,173^{\star \star \star} \\
(0,024) \\
\end{array}$ \\
\hline$\Delta P a a_{t-2}$ & - & - & - & & $\begin{array}{l}0,045^{\star *} \\
(0,022)\end{array}$ \\
\hline$Q^{*}$ & $\begin{array}{l}0,018^{\star \star} \\
(0,089)\end{array}$ & $\begin{array}{l}0,209^{* *} \\
(0,087)\end{array}$ & $\begin{array}{l}0,440^{*} \\
0,253\end{array}$ & - & $\begin{array}{l}0,381^{\star *} \\
(0,149)\end{array}$ \\
\hline$Q_{t-7}^{*}$ & - & - & - & $\begin{array}{c}0,149^{\star \star \star} \\
(0,053)\end{array}$ & - \\
\hline$Q_{t-8}^{*}$ & - & - & - & - & $\begin{array}{c}-0,296^{* *} \\
(0,120) \\
\end{array}$ \\
\hline$V 1_{t-1}$ & $\begin{array}{c}-0,324^{\star \star *} \\
(0,101)\end{array}$ & $\begin{array}{l}-0,031^{*} \\
(0,009)\end{array}$ & $\begin{array}{l}-0,015^{\star} \\
(0,009)\end{array}$ & $\begin{array}{l}-0,043^{*} \\
(0,011)\end{array}$ & $\begin{array}{l}-0,011^{*} \\
(0,006)\end{array}$ \\
\hline Const. & $\begin{array}{c}-0,053^{\text {ns }} \\
(0,063)\end{array}$ & $\begin{array}{l}0,016^{\star} \\
(0,066)\end{array}$ & $\begin{array}{l}-0,152^{*} \\
(0,089)\end{array}$ & $\begin{array}{c}-0,080^{\star *} \\
(0,036)\end{array}$ & $\begin{array}{l}-0,011^{\text {ns }} \\
(0,041)\end{array}$ \\
\hline tend. & - & $\begin{array}{l}0,0001^{\star *} \\
(0,0003)\end{array}$ & - & - & - \\
\hline$\overline{R^{2}}$ & 0,7450 & 0,8151 & 0,8499 & 0,8515 & 0,8699 \\
\hline Estatist. F & 14,75 & 20,59 & 17,54 & 18,91 & 24,87 \\
\hline \multicolumn{6}{|l|}{ Testes } \\
\hline Hausman & - & - & $-4,56^{*}$ & - & \\
\hline Autocor. & $1,038^{\text {ns }}$ & $0,004^{\mathrm{ns}}$ & $0,521^{\mathrm{ns}}$ & $0,065^{\mathrm{ns}}$ & $-0,007^{\text {ns }}$ \\
\hline Heteroc. & $4,36^{\text {ns }}$ & $25,679^{\text {ns }}$ & $18,97^{\mathrm{ns}}$ & $9,44^{\mathrm{ns}}$ & $0,99^{\mathrm{ns}}$ \\
\hline Reset & $4,66^{\text {ns }}$ & $1,30^{\mathrm{ns}}$ & $2,39^{\text {ns }}$ & $4,01^{\mathrm{ns}}$ & $0,94^{\mathrm{ns}}$ \\
\hline Sargan+ & - & - & $3,676^{\text {ns }}$ & - & - \\
\hline
\end{tabular}

Fonte: Resultados da pesquisa.

$\left({ }^{* *}\right)$ significativo a $\left.1 \%,{ }^{* *}\right)$ significativo a $5 \%,\left(^{*}\right)$ significativo a $10 \%$, ns, não significativo. 
A variável $Q^{*}$ foi calculada a partir dos coeficientes dos parâmetros de longo prazo, preço $\left(\theta_{p}\right)$ e variável de interação $\left(\theta_{p z}\right)$, obtidos nas equações de demanda. Algumas variáveis defasadas incluídas no modelo geral foram excluídas das relações de ofertas. A variável dependente $\Delta P$ apresentou processo autorregressivo apenas para o Norte. Portanto, nas demais regiões nenhuma das defasagens resultantes foi estatisticamente significativa e, portanto, não aparecem no modelo parcimonioso.

A respeito da variável quantidade, os coeficientes contemporâneos estimados nas regiões Sul e Nordeste mostraram-se positivamente correlacionados com o preço da gasolina C. Entretanto, nas demais delimitações geográficas as quantidades correntes não se mostraram significativas. No longo prazo, exceto na região Centro-Oeste, a quantidade também apresentou impactos positivos e significativos sobre o preço da gasolina C.

Com relação aos preços dos insumos, gasolina A e álcool anidro, as estimativas dos coeficientes correntes foram positivas e estatisticamente significativas. No caso dos preços da gasolina A, as defasagem 1 e 2 no Nordeste, 2 e 8 no Norte e primeira defasagem no Centro - Oeste apresentaram-se negativas. Entretanto, o efeito cumulativo de longo prazo do preço da gasolina A foi positivo. A respeito do preço do álcool anidro, a maioria das defasagens estimadas foi positiva. Destaca-se que os efeitos cumulativos de longo foram todos positivos.

O coeficiente do vetor de correção de erros $V 1_{t-1}$, que determina a velocidade de ajustamento em direção ao equilíbrio de longo prazo, foi significativo para todas as delimitações geográficas, embora tenha se revelado baixo na maioria delas.

A Tabela 6 apresenta os resultados dos coeficientes de longo prazo da relação de oferta, assim como os parâmetros que determinam o grau de poder de mercado de longo prazo no modelo dinâmico. 
Tabela 6 - Coeficientes de Longo Prazo da relação de Oferta do Modelo Dinâmico

Solução estática de longo prazo

\begin{tabular}{|c|c|c|c|c|c|}
\hline Variável & Sudeste & Sul & Nordeste & Norte & Centro-Oeste \\
\hline Constante & $\begin{array}{c}-0,053^{\text {ns }} \\
(0,063)\end{array}$ & $\begin{array}{l}0,016^{* *} \\
(0,007)\end{array}$ & $\begin{array}{l}-0,152^{*} \\
(0,089)\end{array}$ & $\begin{array}{c}0,041^{\text {ns }} \\
(0,04)\end{array}$ & $\begin{array}{c}-0,011^{\text {ns }} \\
(0,041)\end{array}$ \\
\hline$\left(\xi_{q}\right)$ & $\begin{array}{l}0,0002^{\star \star} \\
(0,0001)\end{array}$ & $\begin{array}{c}0,001^{* \star} \\
(0,0004)\end{array}$ & $\begin{array}{l}0,0009^{\star} \\
(0,0005)\end{array}$ & $\begin{array}{c}0,009^{* * *} \\
(0,001)\end{array}$ & $\begin{array}{l}0,001^{\mathrm{ns}} \\
(0,002)\end{array}$ \\
\hline$\left(\xi_{p a a}\right)$ & $\begin{array}{l}0,084^{* *} \\
(0,039)\end{array}$ & $\begin{array}{c}0,187^{\star * *} \\
(0,030)\end{array}$ & $\begin{array}{c}0,145^{\star \star *} \\
(0,028)\end{array}$ & $\begin{array}{l}0,036^{\text {ns }} \\
(0,231)\end{array}$ & $\begin{array}{c}0,357^{\star * *} \\
(0,041)\end{array}$ \\
\hline$\left(\xi_{p g a}\right)$ & $\begin{array}{c}0,0867^{\star \star *} \\
(0,112)\end{array}$ & $\begin{array}{c}2,403^{\star \star \star} \\
(0,13)\end{array}$ & $\begin{array}{l}0,102^{\text {ns }} \\
(0,168)\end{array}$ & $\begin{array}{l}-0,006^{\text {ns }} \\
(0,042)\end{array}$ & $\begin{array}{c}0,039^{\star \star *} \\
(0,011)\end{array}$ \\
\hline$\Lambda$ & $\begin{array}{c}0,018^{\star \star} \\
(0,09)\end{array}$ & $\begin{array}{l}0,209^{\star *} \\
(0,087)\end{array}$ & $\begin{array}{l}0,440^{*} \\
(0,253)\end{array}$ & $\begin{array}{l}0,068^{*} \\
(0,034)\end{array}$ & $\begin{array}{l}0,085^{\star *} \\
(0,033)\end{array}$ \\
\hline
\end{tabular}

Estimativas dos componentes individuais de V1 no longo prazo

\begin{tabular}{cccccc}
\hline Variável & Sudeste & Sul & Nordeste & Norte & Centro-Oeste \\
\hline$P g_{t-1}$ & $-0,324$ & $-0,031$ & $-0,015$ & $-0,043$ & $-0,011$ \\
\hline$P a a_{t-1}$ & 0,099 & 0,079 & 0,032 & 0,095 & 0,031 \\
\hline$P g a_{t-1}$ & 0,340 & - & - & - & - \\
\hline
\end{tabular}

Fonte: Resultados da pesquisa.

$\left({ }^{* * *}\right)$ indica significativo a $1 \%,\left({ }^{* *}\right)$ indica significativo a $5 \%,\left({ }^{*}\right)$ indica significativo a $10 \%$, ns, não significativo.

Os valores entre parênteses referem-se aos desvios-padrão que foram calculados a partir da transformação de Bardsen (1989).

Todas as variáveis especificadas na estimação das relações de ofertas apresentaram sinais coerentes com a teoria econômica. Para todas as regiões, os preços do álcool anidro e gasolina A mostraram-se positivamente correlacionados com o preço da gasolina C.

Com relação ao parâmetro que determina o grau de poder de mercado no modelo dinâmico, $\Lambda$, os coeficientes contemporâneos foram positivos e estatisticamente significativos, porém, relativamente baixos. Portanto, os valores revelaram-se distantes daqueles que deveriam prevalecer para comportamentos colusivos. Entretanto, tais resultados não permitiram aceitar a hipótese de que as empresas ajam como tomadoras de preços. 
Especificamente, nas regiões Sudeste e Sul, os parâmetros estimados no modelo dinâmico evidenciaram a ausência de comportamento colusivo. Nessas regiões concentram-se o maior número de empresas. Este fato pode explicar, parcialmente, os resultados encontrados para o parâmetro de conduta de longo prazo. Além disso, o comércio intrarregional também pode funcionar como elemento impeditivo ao exercício de poder de mercado por parte das empresas locais. Nesse sentido, se essas distribuidoras estabelecem preços abusivos, poderá perder parcelas de mercado, em razão da concorrência de distribuidoras localizadas nas regiões mais próximas. Por outro lado, a significância estatística desses parâmetros sugere que as empresas distribuidoras de gasolina $\mathrm{C}$ não agem como tomadora de preços nessas duas regiões.

No Norte e Centro-Oeste os parâmetros de conduta de longo prazo mostraram-se estatisticamente significativos e positivos. Entretanto, apesar de haver um número relativamente pequeno de distribuidoras atuando nessas regiões, especialmente no Norte, o grau de competição refletido pelo parâmetro foi bastante elevado. Nessas regiões o total de combustível comercializado é relativamente baixo, o volume de vendas de gasolina $\mathrm{C}$ no Norte e Centro-Oeste representam as menores médias nacionais. Sugere-se que uma demanda permanentemente reprimida impõe um limite natural ao exercício de poder de mercado das empresas distribuidoras que vendem a gasolina $\mathrm{C}$. Também, provavelmente, nessas regiões outras alternativas de locomoção, como, por exemplo, o transporte público, são bastante utilizados. Na região Nordeste, o parâmetro de conduta estimado no modelo dinâmico foi comparativamente maior que nas demais regiões. A competição entre as 21 empresas distribuidoras que atuam nessa região exibe algum grau de imperfeição, porém, revelou-se distante do comportamento colusivo.

Os resultados obtidos para os parâmetros de conduta de longo prazo não foram consistentes com a hipótese de que as empresas distribuidoras de gasolina $C$ ajam como tomadoras de preços $(\Lambda=0)$. No outro extremo, a hipótese de conluio perfeito $(\Lambda=1)$ entre elas também foi rejeitada. Existe uma clara indicação de que a competição entre as empresas que atuam regionalmente apresenta algum grau de imperfeição no longo prazo. Entretanto, nas regiões Sudeste, Norte e Centro-Oeste os parâmetros comportamentais refletem a elevada competição entre as distribuidoras não associada às condi- 
ções estruturais dos mercados. No Sul e Nordeste, os parâmetros foram comparativamente mais elevados, porém, distantes do conluio perfeito. A concentração de mercado verificada regionalmente pode ser explicada pela elevada eficiência das grandes distribuidoras de gasolina $\mathrm{C}$, assim como pela necessidade dos altos investimentos em capital. Sobre o exercício do poder de mercado das distribuidoras de gasolina $\mathrm{C}$, destaca-se que, a possibilidade de substituir gasolina $\mathrm{C}$ por álcool hidratado, ou outras alternativas de locomoção, no longo prazo, podem explicar, pelo menos em parte, os resultados encontrados para os parâmetros de conduta.

\section{Conclusões}

O segmento de distribuição de gasolina $\mathrm{C}$ apresenta características que potencializam o exercício de poder de mercado. Além disso, suspeitas sobre a conduta anticoncorrencial por parte das distribuidoras são frequentemente levantadas junto aos órgãos de defesa da concorrência. Diante desse cenário, no presente artigo, avaliou-se o grau de poder de mercado das distribuidoras de gasolina $\mathrm{C}$ nas regiões brasileiras, no período de 2002 a 2008.

Concluiu-se, a partir dos resultados dos modelos dinâmico e estático, que não existe poder de mercado expressivo por parte das distribuidoras de gasolina $\mathrm{C}$ nos mercados regionais. Portanto, em nível regional, a hipótese de conluio perfeito entre elas foi rejeitada. No outro extremo, exceto na região Norte para o modelo estático, as empresas distribuidoras de gasolina $\mathrm{C}$ não agem como tomadoras de preços. Porém, conforme verificado anteriormente pelas estimativas dos modelos estático e dinâmico, em algumas regiões os parâmetros revelaram-se suficientemente baixos, evidenciando elevada competição entre elas. Sugere-se que a concentração nos mercados regionais pode ser explicada pela elevada eficiência das grandes distribuidoras de gasolina $\mathrm{C}$ e também pela necessidade dos altos investimentos em capital. A possibilidade de substituir gasolina $C$ por álcool hidratado, ou alternativas de locomoção no longo prazo pode limitar, pelo menos em parte, o exercício de poder de mercado por parte das distribuidoras. A Agência Reguladora, a ANP, juntamente com os órgãos de defesa da concorrência também podem estar sendo eficientes no sentido de incentivar uma maior competição no setor. 
Em suma, as distribuidoras de gasolina $C$ não exercem poder de mercado expressivo nas regiões brasileiras. É provável que exista conduta anticoncorrencial em outros segmentos do mercado de gasolina C, como por exemplo, na revenda de gasolina C. Assim, para uma melhor compreensão do poder de determinação dos preços de gasolina $\mathrm{C}$ ao consumidor final, torna-se relevante a realização de uma análise do grau de poder de mercado no segmento de revenda de gasolina C. Como proposta para trabalhos futuros, sugerese a realização de um estudo dessa natureza. Os resultados desses estudos devem motivar decisões políticas e econômicas que visem regular a conduta empresarial das distribuidoras e revendedoras de combustíveis, preservando-se, assim, o bem-estar dos consumidores.

\section{Referências}

ANFAVEA, 2009. Associação Nacional dos Fabricantes de Veículos Automotores, Anuário Estatístico da Indústria Automobilística Brasileira. Brasil.

AGÊNCIA NACIONAL DE PETRÓLEO - ANP. Abastecimento em números. Boletim gerencial. Comportamento do Mercado de Derivados de Petróleo e Biocombustíveis em 2008. Ano 4, $\mathrm{n}^{\circ}$ 21 , fev. 2009a.

AGÊNCIA NACIONAL DE PETRÓLEO - ANP. Vendas pelas Distribuidoras, dos derivados de Combustíveis de Petróleo (metros cúbicos). Disponível em < http://www.anp.gov.br/doc/dados_estatisticos/Vendas_de_Combustiveis_m3.xls. Acesso em fev. 2009b.

B ARDSEN, G., The Estimation of Long-Run Coefficients from Error-Correcting Models. Oxford Bulletin of Economics and Statistics. n. 51, 345-350, 1989.

BASK, M., LUNDGREN, J., RUNDHOLM, N. Market power in the expanding Nordic power market. (2007). HUI Working Paper No. 9.Diponível em http://hui.demo.litium.se/LitiumDokument20/ GetDocument.asp?archive=3\&directory=72\&document=891. Acesso em 14 mar. 2009.

BRESNAHAN, T.F. The Oligopoly Solution Concept is Identified. Economics Letters n. 10, p. 87-92, 1982.

BRUNI, P. P. B. Comportamento dos Preços e a Formação de Cartéis na Etapa do Mercado de Gasolina Brasileiro. 2005. 88p. Disponível em: http://www.gee.ie.ufrj.br/publicacoes/pdf/2005_comp_preco_form_carteis.pdf. Acesso em 10 fev. 2011.

CADE - CONSELHO ADMINISTRATIVO DE DEFESA ECONÔMICA. Ato de concentração $n^{o}$ 08012.002634/2006-73. Disponível em: www.cade.gov.br/plenario/Sessao_385/Relat/10-Relatorio-AC-2006-08012.002634-ALE-Satelite-Azevedo.pdf. Acesso em 05 de maio 2009.

CENTRO DE ESTUDOS AVANCADOS EM ECONOMIA APLICADA - CEPEA. Preços do álcool hidratado. Disponível em < http:/www.cepea.esalq.usp.br/alcool/ Acesso em Mai 2009.

DEODHAR, S.Y.; SHELDON, I.M.,. Market Power in the World Market for Soymeal Exports. Journal of Agricultural and Resource Economics, v.1, n. 3, p. 78-86, 1997.

ENDERS, W. Applied econometric time series. New York: John Wiley, 1995. 433 p.

FEDERAÇÃO NACIONAL DO COMÉRCIO DE COMBUSTÍVEIS E DE LUBRIFICANTES - FECOMBUSTÍVEIS, 2009. Relatório Anual da Revenda de Combustíveis 2009. Disponível em < http://www.fecombustiveis.org.br/relatorio-2009> Acesso em 20 abr. 2009.

Est. Econ., São Paulo, vol. 43, n.3, p. 465-497, jul.-set. 2013 
GOMEZ, J., M., A.. (2009). Demanda de combustíveis por veículos leves e motocicletas no Brasil. 69p. (Dissertação de Mestrado). Faculdades de Economia e Finanças do Ibmec. Rio de Janeiro: Faculdades Ibmec. 2009.

HJALMARSSON, E., Nord Pool: A Power Market Without Market Power, Working paper n 28, department of Economics, Goteborg University, 2000.

INSTITUTO BRASILEIRO DE GEOGRAFIA E ESTATÍSTICA (IBGE). Pesquisa Industrial Mensal. Disponível em:<http://www.ibge.gov.br/>. Acesso em: 18 jul. 2010.

JOHANSEN, S., JUSELIUS, K. Maximum likelihood estimation and inference on cointegration - with application to the demand for money. Oxford Bulletin on Economics and Statistics, v. 52, n. 1, p. 169-210, 1990.

JUDGE, G.G.; GRIFFITHS, W. E.; HILL, R. C.; LÜTKEPOHL, H. Introduction the Theory and Practice of Econometrics. New York: John Wiley, 1988. 1024p.

KARP, L. S., \& PERLOFF, J. M. (1989). Dynamic oligopoly in the rice export market. The Review of Economics and Statistics, 71, 462-470.

NAKANE, M. I., A test of competition in Brazilian banking. Estudos Econômicos. v.32, n.2, p. 203 224, 2002.

NUNES, C.; GOMES, C. Aspectos concorrenciais do varejo de combustíveis no Brasil. In: Encontro Nacional de Economia, 33, 2005, Natal - RN. Anais... Brasília: ANPEC, 2005.

LAU, L.J.. On Identifying the Degree of Competitiveness from Industry Price and Output Data. Economics Letters n. 10, v.1, p. 93-99, 1982.

PINTO, M.R; SILVA, E.C.D. O Brilho da Bandeira Branca: Concorrência no Mercado de Combustíveis no Brasil, 2004. Disponível em: <www.anpec.org.br/encontro2004/Artigo/A04A086pdf.> Acesso em: 14 de Mar. 2009.

SALVO, A. O método de Bresnahan-Lau: uma nota cautelar sobre a sua aplicabilidade. Revista de Direito da Concorrência, 18, 2008, 11-50.

SALVO, A. Inferring market power under the threat of entry: the case of the Brazilian cement industry. RAND Journal of Economics Vol. 41, No. 2, Summer, 2010, pp. 326-350.

SARGAN, J.D. (Ed.), Wages and prices in the United Kingdom: A study in econometric methodology. Butterworth, London. Reprinted in D.F. Hendry and K.F. Wallis, Econometrics and Quantitative Economics, Basil Blackwell Oxford, 1964.

SCHÜNEMANN, L. (2007). A demanda de gasolina automotiva no Brasil: o impacto nas elasticidades de curto e longo prazo da expansão do GNV e dos carros flex. 107p. (Dissertação de Mestrado). Faculdades de Economia e Finanças do Ibmec. Rio de Janeiro: Faculdades Ibmec. 2007.

STEEN, F., SALVANES, K.G. Testing for market power using a dynamic oligopoly model. International Journal of Industrial Organization. v.17, n. 1, p. 147-177, 1999.

SUSANTO, D. Measuring the Degree of Market Power in the Export Demand for Soybean Complex. Louisiana: Department of Agricultural Economics and Agribusiness, 2006. 180p. (Tese).

VASSILOPOULOS, P. Models for the identification of Market Power in wholesale electricity markets. University Paris IX Dauphine. Paris: Department of Economics and Agribusiness, 2003. 102p. (Tese).

ZEIDAN, R.; RESENDE, M. (2009). Measuring Market Conduct in the Brazillian Cement Industry: A Dynamic Econometric Investigation. Review Industrial Organization. 34, p. 231-244. 


\section{Apêndice}

Tabela 1 A - Resultados das variáveis dummies nas equações de demanda modelo estático

\begin{tabular}{|c|c|c|c|c|c|}
\hline Variável & Sudeste & Sul & Nordeste & Norte & Centro - Oeste \\
\hline fevereiro & $\begin{array}{c}-29,788^{\star *} \\
(15,147)\end{array}$ & $\begin{array}{c}-19,291^{\star \star} \\
(8,452)\end{array}$ & $\begin{array}{c}-39,024^{* \star *} \\
(5,492)\end{array}$ & $\begin{array}{c}-7,048^{\star \star \star} \\
(2,577)\end{array}$ & $\begin{array}{l}-7,469^{*} \\
(4,469)\end{array}$ \\
\hline marco & $\begin{array}{l}19,523^{\text {ns }} \\
(16,787)\end{array}$ & $\begin{array}{c}-16,964^{\star *} \\
(9,261)\end{array}$ & $\begin{array}{c}-31,960^{* * *} \\
(5,91)\end{array}$ & $\begin{array}{c}-4,705^{\star \star \star} \\
(2,866)\end{array}$ & $\begin{array}{c}18,817^{\star * \star} \\
(5,270)\end{array}$ \\
\hline abril & $\begin{array}{l}21,195^{\text {ns }} \\
(15,057)\end{array}$ & $\begin{array}{c}-21,038^{\star *} \\
(8,388)\end{array}$ & $\begin{array}{c}-37,53^{\star \star \star} \\
(5,504)\end{array}$ & $\begin{array}{c}-5,953^{\star \star \star} \\
(2,684)\end{array}$ & $\begin{array}{l}9,626^{\star \star} \\
(4,029)\end{array}$ \\
\hline maio & $\begin{array}{l}15,765^{\text {ns }} \\
(16,346)\end{array}$ & $\begin{array}{c}-28,647^{\star \star *} \\
(8,991)\end{array}$ & $\begin{array}{c}-39,007^{* \star *} \\
(6,268)\end{array}$ & $\begin{array}{c}-7,134^{\star \star} \\
(2,85)\end{array}$ & $\begin{array}{c}11,369^{\star * *} \\
(4,37)\end{array}$ \\
\hline junho & $\begin{array}{c}-12,018^{\text {ns }} \\
(15,521)\end{array}$ & $\begin{array}{c}-37,491^{\text {ns }} \\
(8,53)\end{array}$ & $\begin{array}{c}-35,044^{* \star \star} \\
(6,083)\end{array}$ & $\begin{array}{c}-7,532^{\star \star \star} \\
(2,622)\end{array}$ & $\begin{array}{l}7,024^{*} \\
(3,97)\end{array}$ \\
\hline julho & $\begin{array}{l}5,514^{\mathrm{ns}} \\
(16,712)\end{array}$ & $\begin{array}{c}-24,061^{\star \star \star} \\
(9,226)\end{array}$ & $\begin{array}{c}-27,49^{\star * *} \\
(6,632)\end{array}$ & $\begin{array}{l}-0,762^{\text {ns }} \\
(2,699)\end{array}$ & $\begin{array}{c}14,412^{\star \star *} \\
(4,512)\end{array}$ \\
\hline agosto & $\begin{array}{c}4,106^{\mathrm{ns}} \\
(17,642)\end{array}$ & $\begin{array}{c}-25,249^{* *} \\
(9,760)\end{array}$ & $\begin{array}{c}-27,226^{* * *} \\
(7,229)\end{array}$ & $\begin{array}{l}-0,413^{\text {ns }} \\
(2,852)\end{array}$ & $\begin{array}{c}12,483^{\star \star \star} \\
(4,563)\end{array}$ \\
\hline setembro & $\begin{array}{l}2,747^{\mathrm{ns}} \\
(17,374)\end{array}$ & $\begin{array}{c}-25,583^{\star \star *} \\
(9,610)\end{array}$ & $\begin{array}{c}-22,698^{* * *} \\
(6,463)\end{array}$ & $\begin{array}{l}2,155^{\mathrm{ns}} \\
(2,801)\end{array}$ & $\begin{array}{l}5,706^{\mathrm{ns}} \\
(4,476)\end{array}$ \\
\hline outubro & $\begin{array}{l}22,864^{\text {ns }} \\
(19,474)\end{array}$ & $\begin{array}{l}-22,486^{\star *} \\
(10,646)\end{array}$ & $\begin{array}{c}-13,786^{*} \\
(7,339)\end{array}$ & $\begin{array}{l}1,326^{\mathrm{ns}} \\
(3,157)\end{array}$ & $\begin{array}{c}10,635^{\star \star *} \\
(4,776)\end{array}$ \\
\hline novembro & $\begin{array}{l}-26,854^{\text {ns }} \\
(16,873)\end{array}$ & $\begin{array}{c}-34,618^{\star \star \star} \\
(9,371)\end{array}$ & $\begin{array}{l}-32,796^{*} \\
(6,164)\end{array}$ & $\begin{array}{l}-3,867^{\text {ns }} \\
(2,792)\end{array}$ & $\begin{array}{l}1,494^{\mathrm{ns}} \\
(4,112)\end{array}$ \\
\hline dezembro & $\begin{array}{c}156,547^{\star \star *} \\
(14,433)\end{array}$ & $\begin{array}{c}69,077^{* * *} \\
(8,049)\end{array}$ & $\begin{array}{l}24,98^{\star \star *} \\
(5,129)\end{array}$ & $\begin{array}{c}14,335^{\star *} \\
(2,429)\end{array}$ & $\begin{array}{c}40,084^{\star * \star} \\
(3,926)\end{array}$ \\
\hline
\end{tabular}

Fonte: Dados da pesquisa

$\left({ }^{* *}\right)$ significativo a $1 \%,\left({ }^{* *}\right)$ significativo a $5 \%,\left(^{*}\right)$ significativo a $10 \%$ e ns, não significativo.

Tabela 2 A - Resultados das variáveis dummies nas equações de relação de oferta - modelo estático

\begin{tabular}{|c|c|c|c|c|c|}
\hline Variável & Sudeste & Sul & Nordeste & Norte & Centro-Oeste \\
\hline \multirow{2}{*}{ fevereiro } & $-0,014^{\text {ns }}$ & $-22,599^{*}$ & $0,039^{*}$ & $0,144^{\text {ns }}$ & $0,018^{\text {ns }}$ \\
\hline & $(0,015)$ & $(13,681)$ & $(0,023)$ & $(0,098)$ & $(0,012)$ \\
\hline \multirow{2}{*}{ marco } & $-0,003^{\text {ns }}$ & $7,609^{\text {ns }}$ & $0,033^{*}$ & $-0,028^{\text {ns }}$ & $-0,017^{\text {ns }}$ \\
\hline & $(0,047)$ & $(16,635)$ & $(0,017)$ & $(0,045)$ & $(0,013)$ \\
\hline \multirow{2}{*}{ abril } & $0,007^{\text {ns }}$ & $0,094^{\star *}$ & $0,046^{\star \star}$ & $0.062^{* \star}$ & $-0,009^{n s}$ \\
\hline & $(0,015)$ & $(0,043)$ & $(0,02)$ & $(0,029)$ & $(0,012)$ \\
\hline \multirow{2}{*}{ maio } & $0,018 \mathrm{~ns}$ & $0,112^{\star \star \star}$ & $0,040^{* *}$ & $0,042^{\text {ns }}$ & $0,013^{\star \star \star}$ \\
\hline & $(0,016)$ & $(0,043)$ & $(0,018)$ & $(0,041)$ & $(0,034)$ \\
\hline \multirow{2}{*}{ junho } & $0,007^{\text {ns }}$ & $0.076^{\star \star \star}$ & $0,032^{*}$ & $0,138^{\text {ns }}$ & $-0,001^{n s}$ \\
\hline & $(0,014)$ & $(0.02)$ & $(0,018)$ & $(0,155)$ & $(0,018)$ \\
\hline \multirow{2}{*}{ julho } & $-0,006^{n s}$ & $0,145^{\star *}$ & $0,013^{\text {ns }}$ & $0,138^{\text {ns }}$ & $-0,030^{* *}$ \\
\hline & $(0,014)$ & $(0,039)$ & $(0,015)$ & $(0,113)$ & $(0,014)$ \\
\hline \multirow{2}{*}{ agosto } & $-0,005^{\text {ns }}$ & $0,043^{\text {ns }}$ & $0,005^{\mathrm{ns}}$ & $0,160^{\text {ns }}$ & $-0,025^{\star}$ \\
\hline & $(0,015)$ & $(0,037)$ & $(0,014)$ & $(0,133)$ & $(0,014)$ \\
\hline \multirow{2}{*}{ setembro } & $-0,0009^{\text {ns }}$ & $0,065^{\text {ns }}$ & $0,011^{\text {ns }}$ & $0,119^{\text {ns }}$ & $-0,0265^{*}$ \\
\hline & $(0,014)$ & $(0,041)$ & $(0,012)$ & $(0,102)$ & $(0,014)$ \\
\hline \multirow{2}{*}{ outubro } & $-0,107^{*}$ & $0,003^{\text {ns }}$ & $-0,005^{\text {ns }}$ & $0,137^{\text {ns }}$ & $-0,024^{*}$ \\
\hline & $(0,063)$ & $(0,035)$ & $(0,011)$ & $(0,100)$ & $(0,015)$ \\
\hline \multirow{2}{*}{ novembro } & $0,002^{\text {ns }}$ & $0,089^{*}$ & $0,021^{\text {ns }}$ & $0,009^{\text {ns }}$ & $-0,013^{\text {ns }}$ \\
\hline & $(0,013)$ & $(0,048)$ & $(0,016)$ & $(0,038)$ & $(0,011)$ \\
\hline \multirow{2}{*}{ dezembro } & $-0,060^{* *}$ & $-0.247^{\star \star}$ & $-0,031^{*}$ & $0,231^{\text {ns }}$ & $-0,05^{\star *}$ \\
\hline & $(0,029)$ & $(0,115)$ & $(0,016)$ & $(0,695)$ & $(0,021)$ \\
\hline
\end{tabular}

Fonte: Dados da pesquisa

$\left({ }^{* * *}\right)$ significativo a $1 \%,\left({ }^{* *}\right)$ significativo a $5 \%,\left({ }^{*}\right)$ significativo a $10 \%$ e ns, não significativo 
Tabela 3 A - Resultados do teste $A D F$ pelo procedimento descrito em Enders (1995)

\begin{tabular}{|c|c|c|c|c|c|}
\hline \multirow[t]{2}{*}{ Variável } & \multirow{2}{*}{$\begin{array}{c}\text { Nível } \\
\text { Defasagens }\end{array}$} & \multirow[b]{2}{*}{$t$} & \multicolumn{2}{|c|}{ Primeira diferença } & \multirow[t]{2}{*}{ Conclusão } \\
\hline & & & Defasagens & $t$ & \\
\hline PgSE & 1 & 1,20 & 1 & $-4,86^{\star \star \star}$ & $\mathrm{I}(1)$ \\
\hline PaSE & 3 & $-0,20$ & 0 & $-9,59^{\star \star \star}$ & $\mathrm{I}(1)$ \\
\hline PgS & 1 & 1,06 & 1 & $-4,65^{\star \star \star}$ & $\mathrm{I}(1)$ \\
\hline $\mathrm{PaS}$ & 3 & $-0,22$ & 0 & $-5,57^{\star \star \star}$ & $\mathrm{I}(1)$ \\
\hline PgNE & 1 & 1,36 & 0 & $-5,56^{\star \star \star}$ & $\mathrm{I}(1)$ \\
\hline PaNE & 1 & $-0,14$ & 1 & $-4,60^{\star \star \star}$ & $\mathrm{I}(1)$ \\
\hline $\mathrm{PgN}$ & 1 & 1,36 & 1 & $-4,57^{\star \star \star}$ & $\mathrm{I}(1)$ \\
\hline $\mathrm{PaN}$ & 1 & 0,05 & 0 & $-4,61^{\star \star \star}$ & $\mathrm{I}(1)$ \\
\hline $\mathrm{PgCO}$ & 1 & 1,26 & 1 & $-4,88^{\star \star \star}$ & $\mathrm{I}(1)$ \\
\hline $\mathrm{PaCO}$ & 3 & $-0,27$ & 1 & $-6,09^{\star \star \star}$ & $\mathrm{l}(1)$ \\
\hline $\mathrm{PAA}_{1}{ }^{*}$ & 0 & $-0,183$ & - & $-4,31^{\star \star *}$ & $\mathrm{I}(1)$ \\
\hline $\mathrm{PAA}_{2}{ }^{*}$ & 0 & 0,25 & 0 & $-7,49^{\star \star \star}$ & $\mathrm{I}(1)$ \\
\hline PgaSE & 3 & 1,34 & 0 & $8,54^{\star \star *}$ & $\mathrm{I}(1)$ \\
\hline PgaS & 0 & $-4,01^{\star \star \star}$ & - & - & $I(0)$ \\
\hline PgaNE & 1 & $-3,72^{\star \star \star}$ & - & - & $\mathrm{I}(0)$ \\
\hline PgaN & 1 & $3,52^{\star \star \star}$ & - & - & $\mathrm{I}(0)$ \\
\hline $\mathrm{PgaCO}$ & 1 & $3,82^{\star \star \star}$ & - & - & $\mathrm{I}(0)$ \\
\hline PZSE & 1 & $-0,94$ & 0 & $11,59^{\star \star \star}$ & $\mathrm{I}(1)$ \\
\hline PZS & 1 & $-0,92$ & 0 & $11,50^{\star \star \star}$ & $I(1)$ \\
\hline PZNE & 1 & $-0,91$ & 0 & $-11,75^{\star \star \star}$ & $I(1)$ \\
\hline PZN & 1 & $-0,93$ & 0 & $-11,78^{\star \star \star}$ & $\mathrm{I}(1)$ \\
\hline PZCO & 1 & $-0,92$ & 0 & $-11,56^{\star \star \star}$ & $\mathrm{I}(1)$ \\
\hline QgSE & 11 & $-6,46^{\star \star \star}$ & - & - & $I(0)$ \\
\hline QgS & 0 & $-8,74^{\star \star \star}$ & - & - & $I(0)$ \\
\hline QgNE & 0 & $-7,11^{\star \star \star}$ & - & - & $I(0)$ \\
\hline $\mathrm{QgN}$ & 11 & $-4,87^{\star \star \star}$ & - & - & $I(0)$ \\
\hline $\mathrm{QgCO}$ & 0 & $-7,43^{\star \star \star}$ & - & - & $I(0)$ \\
\hline VACL & 1 & $-1,43$ & 0 & $-11,86^{\star \star *}$ & $I(1)$ \\
\hline$Y$ & 11 & $4,60^{\star \star \star}$ & - & - & $I(0)$ \\
\hline
\end{tabular}

Fonte: Resultados da pesquisa.

$\left({ }^{* * *}\right)$ indica significativo a $1 \%$. 
Tabela $4 \mathrm{~A}$ - Teste de Cointegração na equação de demanda, entre Pg, Pa e PZ

\begin{tabular}{|c|c|c|c|c|c|}
\hline & Hipótese nula & $\tau_{\text {trace }}$ & Valor crítico & $\tau_{\max }$ & Valor crítico \\
\hline \multirow[t]{2}{*}{ Sudeste } & $r=0$ & $44,833^{\star \star}$ & 39,755 & $25,404^{\star *}$ & 23,441 \\
\hline & $r \leq 1$ & 19,429 & 23,342 & 14,136 & 17,234 \\
\hline \multirow[t]{2}{*}{ Sul } & $r=0$ & $26,345^{\star \star}$ & 24,276 & $18,809^{* *}$ & 17,797 \\
\hline & $r \leq 1$ & 7,536 & 12,321 & 7,352 & 11,224 \\
\hline \multirow[t]{2}{*}{ Nordeste } & $r=0$ & $56,001^{*}$ & 41,195 & $32,259^{*}$ & 27,067 \\
\hline & $r \leq 1$ & 23,741 & 25,078 & 17,798 & 20,161 \\
\hline \multirow[t]{2}{*}{ Norte } & $r=0$ & $49,068^{\star *}$ & 41,195 & $28,309^{\star *}$ & 27,067 \\
\hline & $r \leq 1$ & 20,759 & 25,078 & 14,428 & 20,161 \\
\hline \multirow[t]{2}{*}{ Centro-Oeste } & $r=0$ & $49,246^{\star \star}$ & 41,195 & $26,109^{\star \star}$ & 27,068 \\
\hline & $r \leq 1$ & 23,136 & 25,078 & 17,261 & 20,161 \\
\hline
\end{tabular}

Vetores de Cointegração na forma normalizada

\begin{tabular}{lcccc}
\hline P1 & Pg & $P a$ & $P Z$ & $c$ \\
\hline Sudeste & 1,000000 & $-0,734468$ & $-0,0000008$ & $-1,904000$ \\
\hline Sul & 1,000000 & $-0,677508$ & $-0,000002$ & $-1,380450$ \\
\hline Nordeste & 1,000000 & $-0,611162$ & $-0,000003$ & $-1,447253$ \\
\hline Norte & 1,000000 & $-0,256122$ & $-0,000003$ & $-2,005252$ \\
\hline Centro-Oeste & 1,000000 & $-0,404917$ & $-0,000003$ & $-1,869784$ \\
\hline
\end{tabular}

Fonte: Resultados da pesquisa.

$\left({ }^{* *}\right)$ e $\left({ }^{*}\right)$ refere-se aos valores críticos a $5 \%$ e $1 \%$ de significância.

Tabela 5 A - Teste de cointegração nas variáveis I(1) nas relações de oferta

\begin{tabular}{lccccc}
\hline & Hipótese nula & $\tau_{\text {trace }}$ & Valor crítico & $\tau_{\text {max }}$ & Valor crítico \\
\hline Sudeste & $r=0$ & $61,503^{*}$ & 29,513 & $40,440^{\star}$ & 22,252 \\
& $r \leq 1$ & 21,063 & 16,362 & 17,041 & 15,091 \\
\hline Sul & $r=0$ & $17,323^{\star *}$ & 12,321 & $15,349^{\star *}$ & 11,225 \\
& $r \leq 1$ & $1,974^{\star *}$ & 4,130 & 1,9744 & 4,130 \\
\hline Nordeste & $r=0$ & $14,475^{\star *}$ & 12,321 & 12,065 & 11,225 \\
& $r \leq 1$ & 2,410 & 4,130 & 2,410 & 4,130 \\
\hline Norte & $r=0$ & $13,596^{* *}$ & 12,321 & $11,548^{* *}$ & 11.22480 \\
& $r \leq 1$ & 2,048 & 4,130 & 2,048 & 4,130 \\
\hline Centro- Oeste & $r=0$ & $19,889^{\star *}$ & 12,321 & $18,192^{* *}$ & $11,225^{* *}$ \\
& $r \leq 1$ & $1,697^{\star *}$ & 4,130 & 1,697 & 4,130 \\
\hline
\end{tabular}

Vetores de Cointegração na forma normalizada

\begin{tabular}{lccc}
\hline V1 & $\mathrm{Pg}$ & $\mathrm{Paa}$ & Pga \\
\hline Sudeste & 1,000000 & $-0,306026$ & $-1,048867$ \\
\hline Sul & 1,000000 & $-2,548939$ & - \\
\hline Nordeste & 1,000000 & $-2,165094$ & - \\
\hline Norte & 1,000000 & $-2,213633$ & - \\
\hline Centro-Oeste & 1,000000 & $-2,850681$ & - \\
\hline
\end{tabular}

Fonte: Resultados da pesquisa.

$\left({ }^{* *}\right)$ e $\left({ }^{*}\right)$ refere-se aos valores críticos a 5\% e $1 \%$ de significância. 
Tabela 6 A - Resultados dos testes de separabilidade na variável PZ

\begin{tabular}{cccccc}
\hline Hipótese nula & Sudeste & Sul & Nordeste & Norte & Centro-Oeste \\
\hline$H_{0}: \alpha_{1, P Z}=0$ & $15,129^{\star \star \star}$ & $19,145^{\star \star \star}$ & $16,461^{\star \star \star}$ & $40,285^{\star \star \star}$ & $32,020^{\star \star \star}$ \\
\hline
\end{tabular}

Fonte: Resultados da pesquisa.

$\left({ }^{* * *}\right)$ refere-se aos valores críticos a $1 \%$ de significância.

Tabela 7 A - Resultados das variáveis dummies nas equações de demanda modelo estático

\begin{tabular}{|c|c|c|c|c|c|}
\hline Variável & Sudeste & Sul & Nordeste & Norte & Centro - Oeste \\
\hline fevereiro & $\begin{array}{c}-93,897^{\star \star *} \\
(29,468)\end{array}$ & $\begin{array}{c}-13,767^{\star \star \star} \\
(24,468)\end{array}$ & $\begin{array}{l}0,049^{\text {ns }} \\
(0,030)\end{array}$ & $\begin{array}{c}0,894^{* \star *} \\
(0,061)\end{array}$ & $\begin{array}{l}-7,469^{*} \\
(4,469)\end{array}$ \\
\hline marco & $\begin{array}{l}-34,666^{\text {ns }} \\
(32,476)\end{array}$ & $\begin{array}{c}-34,666^{\text {ns }} \\
(32,476)\end{array}$ & $\begin{array}{l}-0,008^{\text {ns }} \\
(0,020)\end{array}$ & $\begin{array}{c}-0,519^{\star *} \\
(0,089)\end{array}$ & $\begin{array}{c}18,817^{\star \star \star} \\
(5,270)\end{array}$ \\
\hline abril & $\begin{array}{l}-48,660^{\text {ns }} \\
(29,566)\end{array}$ & $\begin{array}{l}-48,660^{\text {ns }} \\
(29,566)\end{array}$ & $\begin{array}{l}0,013^{\star} \\
(0,017)\end{array}$ & $\begin{array}{c}-0,289^{* *} \\
(0,098)\end{array}$ & $\begin{array}{l}9,626^{\star *} \\
(4,029)\end{array}$ \\
\hline maio & $\begin{array}{c}-61,645^{\star \star} \\
(31,402)\end{array}$ & $\begin{array}{l}-61,645^{\star *} \\
(31,402)\end{array}$ & $\begin{array}{l}0,007^{\text {ns }} \\
(0,018)\end{array}$ & $\begin{array}{c}0,348^{\star \star \star} \\
(0,124)\end{array}$ & $\begin{array}{c}11,369^{\star \star \star} \\
(4,37)\end{array}$ \\
\hline junho & $\begin{array}{c}-92,877^{\star \star \star} \\
(29,540)\end{array}$ & $\begin{array}{c}-92,877^{\star \star \star} \\
(29,540)\end{array}$ & $\begin{array}{l}0,017^{*} \\
(0,018)\end{array}$ & $\begin{array}{c}-0,387^{\star \star \star} \\
(0,106)\end{array}$ & $\begin{array}{l}7,024^{*} \\
(3,97)\end{array}$ \\
\hline julho & $\begin{array}{l}-44,324^{\mathrm{ns}} \\
(31,719)\end{array}$ & $\begin{array}{l}-44,324^{\mathrm{ns}} \\
(31,719)\end{array}$ & $\begin{array}{c}-0,016^{\text {ns }} \\
(0,018)\end{array}$ & $\begin{array}{c}0,112^{\star \star \star} \\
(0,021)\end{array}$ & $\begin{array}{c}14,412^{\star \star \star} \\
(4,512)\end{array}$ \\
\hline agosto & $\begin{array}{l}-48,993^{*} \\
(33,500)\end{array}$ & $\begin{array}{c}-48,993^{*} \\
(33,500)\end{array}$ & $\begin{array}{c}-0,019^{\text {ns }} \\
(0,020) \\
\end{array}$ & $\begin{array}{c}0,142^{* \star \star} \\
(0,021)\end{array}$ & $\begin{array}{c}12,483^{\star * \star} \\
(4,563)\end{array}$ \\
\hline setembro & $\begin{array}{l}-33,996^{\text {ns }} \\
(33,023)\end{array}$ & $\begin{array}{c}-33,996^{\text {ns }} \\
(33,023)\end{array}$ & $\begin{array}{c}-0,012^{\text {ns }} \\
(0,019)\end{array}$ & $\begin{array}{c}-0,039^{\star *} \\
(0,017)\end{array}$ & $\begin{array}{l}5,706^{\text {ns }} \\
(4,476)\end{array}$ \\
\hline outubro & $\begin{array}{c}-11,070^{\text {ns }} \\
(36,965)\end{array}$ & $\begin{array}{c}-11,070^{\text {ns }} \\
(36,965)\end{array}$ & $\begin{array}{l}-0,036^{\text {ns }} \\
(0,035)\end{array}$ & $\begin{array}{l}0,064^{* \star} \\
(0,029)\end{array}$ & $\begin{array}{c}10,635^{\star \star \star} \\
(4,776)\end{array}$ \\
\hline novembro & $\begin{array}{c}-106,088^{\star \star \star} \\
(32,398)\end{array}$ & $\begin{array}{c}-106,088^{\star * *} \\
(32,398)\end{array}$ & $\begin{array}{l}0,014^{\text {ns }} \\
(0,018)\end{array}$ & $\begin{array}{c}-0,020^{\star *} \\
(0,007)\end{array}$ & $\begin{array}{l}1,494^{\text {ns }} \\
(4,112)\end{array}$ \\
\hline dezembro & $\begin{array}{c}295,081^{\star * \star} \\
(28,09)\end{array}$ & $\begin{array}{c}295,081^{\star * *} \\
(28,09)\end{array}$ & $\begin{array}{l}-0,132^{*} \\
(0,066)\end{array}$ & $\begin{array}{c}-0,047^{\text {ns }} \\
(0,081)\end{array}$ & $\begin{array}{c}40,084^{\star \star \star} \\
(3,926)\end{array}$ \\
\hline
\end{tabular}

Fonte: Dados da pesquisa

$\left({ }^{* * *}\right)$ significativo a $1 \%,\left({ }^{* *}\right)$ significativo a $5 \%,\left(^{*}\right)$ significativo a $10 \%$ e ns, não significativo. 